Supporting Information

Conformal Graphene Directly Synthesized on a Femtosecond Laser-Scribed In-Fiber

Microstructure for High-Energy Ultrafast Optical Pulses

Siam Uddin ${ }^{1,2}$, Sungil Kim ${ }^{3}$, Dohyun Kim³, Jiyeon Choi ${ }^{3,4}$, and Yong-Won Song ${ }^{*}, 1,2$

${ }^{1}$ Center for Opto-Electronic Materials and Devices, Korea Institute of Science and Technology, Seoul 02792, Republic of Korea

${ }^{2}$ Division of Nano \& Information Technology, KIST School, Korea University of Science and Technology, Seoul 02792, Republic of Korea

${ }^{3}$ Department of Laser and Electron Beam Technologies, Korea Institute of Machinery and Materials, Daejeon 34103, Republic of Korea

${ }^{4}$ Division of Nano-Mechatronics, Korea University of Science and Technology, Daejeon 34113, Republic of Korea

*Corresponding author: ysong@kist.re.kr. 


\section{Synthesis of graphene.}

Synthesis process was performed on the in-fiber microstructure to grow ACS graphene (Gf) with the condition as shown in Figure S1. Firstly, $\operatorname{Ar}(1000 \mathrm{sccm})$ was flowed into the furnace for 10 mins. Later, the temperature of the furnace was elevated up to $1050^{\circ} \mathrm{C}$ to start the synthesis process with the catalytic effect from $\gamma-\mathrm{Al}_{2} \mathrm{O}_{3}$. As soon as the temperature rises at $1050^{\circ} \mathrm{C}$, pure $\mathrm{CH}_{4}$ (99.995\%) gas was injected as precursor; the growth process continued for 30 mins. After growth time, the furnace went through a quick cooling process down to $400^{\circ} \mathrm{C}$. Finally, only $\mathrm{H}_{2}$ ( $400 \mathrm{sccm}$ ) gas was flowed through the furnace for 30 mins to finalize the synthesis process.

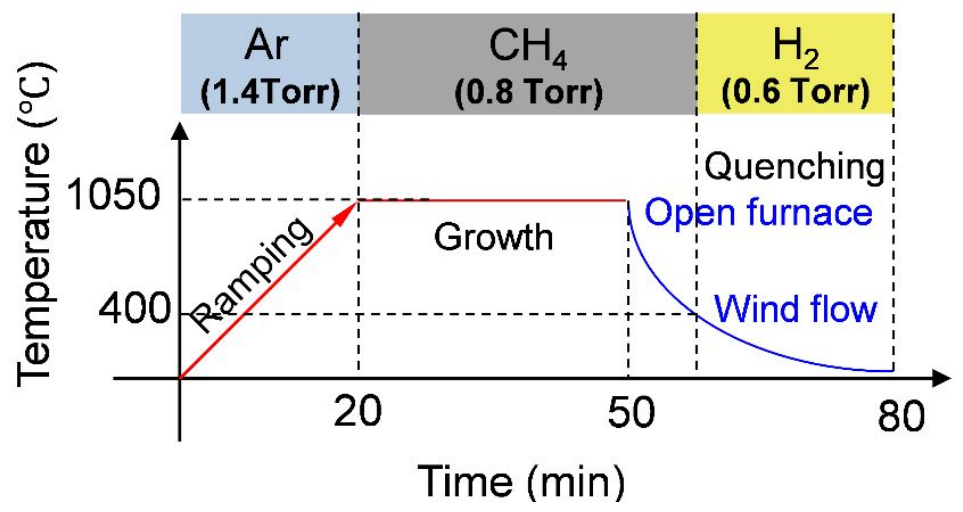

Figure S1. Process scheme for synthesizing ACS Gf. 


\section{Characterization of graphene grown on $\gamma-\mathrm{Al}_{2} \mathrm{O}_{3}$ surface.}

Gf grown on $\gamma-\mathrm{Al}_{2} \mathrm{O}_{3}$ catalyst surface was studied with Raman spectroscopy. The three main characteristic peaks of Gf were found, which can be ascribed to the D-band at $1352 \mathrm{~cm}^{-1}$, G-band at $1600 \mathrm{~cm}^{-1}$ and $2 \mathrm{D}$-band at $2700 \mathrm{~cm}^{-1}$. The calculated average values of $\mathrm{I}_{\mathrm{D}} / \mathrm{I}_{\mathrm{G}}$ (ratio of intensities of $\mathrm{D}$ and $\mathrm{G}$ peaks) and $\mathrm{I}_{2 \mathrm{D}} / \mathrm{I}_{\mathrm{G}}$ (ratio of intensities of $2 \mathrm{D}$ and $\mathrm{G}$ peaks) were found to be 1.01 and 0.65 with an SD of $1.9 \%$ and $2 \%$, respectively. It is important to note that, the growth time was 30 minutes.
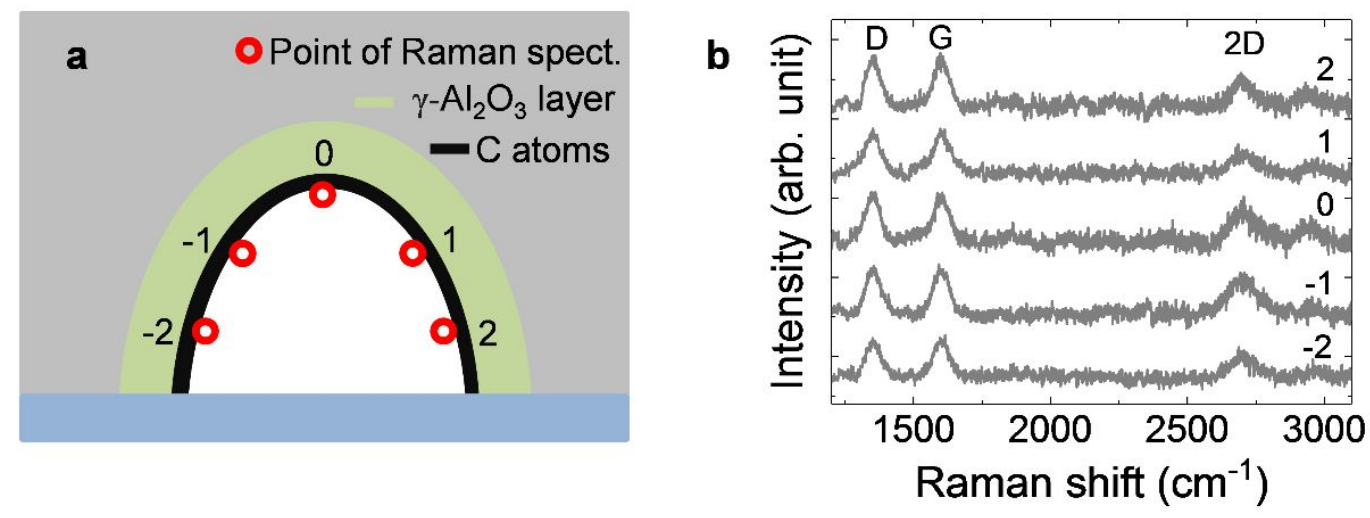

Figure S2. (a) Schematics of the $\gamma-\mathrm{Al}_{2} \mathrm{O}_{3}$ based v-groove that was used for ACS process. (b) Analogous Raman spectra taken from the $\gamma-\mathrm{Al}_{2} \mathrm{O}_{3}$ surface shown in Figure S2a. 


\section{Setup for laser scribing.}

The high repetition pulsed laser $(500 \mathrm{kHz}$ max., temporal pulse width of 1 ps and up to $300 \mathrm{~nJ}$ of pulse energy with $1031 \mathrm{~nm}$ wavelength) was coupled to a galvanometric scanner pair combined with an objective lens $(\mathrm{NA}=0.42,50 \mathrm{X})$ and a motorized stage for moving the sample towards XYZ directions. The laser beam follows a scanning line on the mounted object by the controllable stage with a constant translation speed at a constant pulse repetition rate.

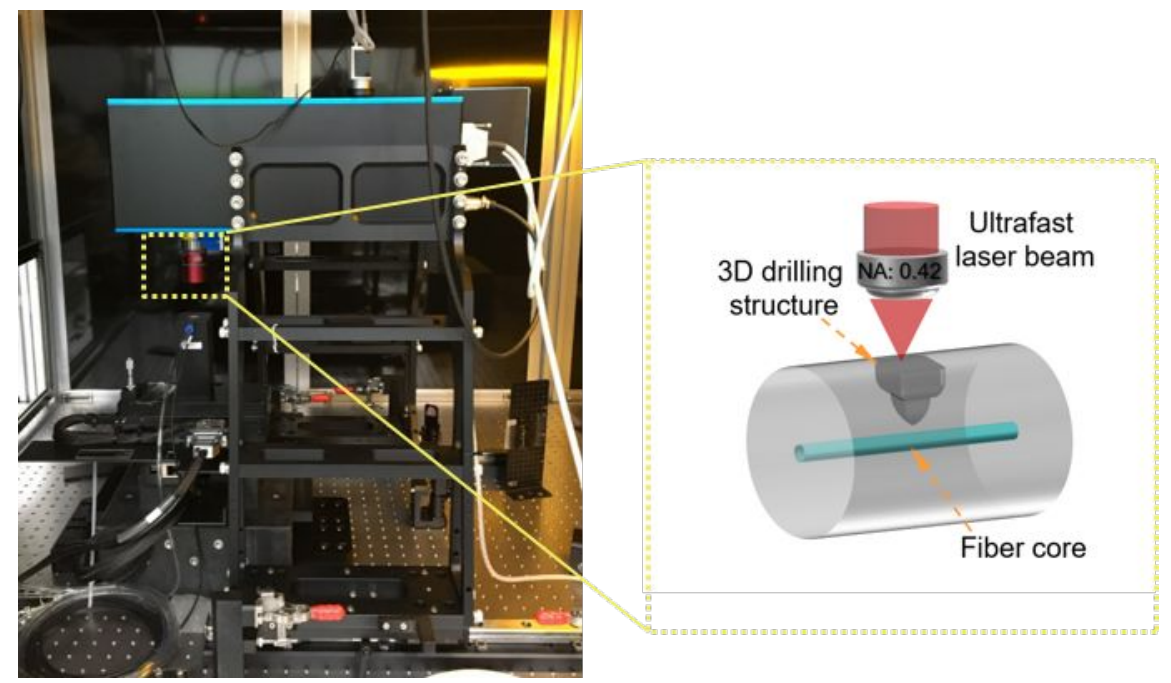

Figure S3. Photograph of the set-up for laser scribing system (left). Magnified illustration of laser scribing process on the fiber (right). 


\section{Critical power for micromachining.}

When light propagates through a dielectric material, oscillating electric dipoles are formed that induces the displacement of the bound charges, leading to the macroscopic polarization which for optical silica with inversion symmetry is given by:

$P=\varepsilon_{0} \chi^{(1)} E+P^{(N L)}=\varepsilon_{0}\left[\chi^{(1)}+\frac{3}{4} \chi^{(3)}|E|^{2}\right] E$

Where, $\chi^{(n)}$ is the n-th order susceptibility.

The second and higher even-order susceptibilities are excluded due to symmetry and negligible contribution. The refractive index can be explained as:

$n=\sqrt{1+\chi^{(1)}+\frac{3}{4} \chi^{(3)}|E|^{2}}=n_{0}+n_{2} I$

Where,

Linear refractive index $n_{0}=\sqrt{1+\chi^{(1)}}$

Nonlinear refractive index $n_{2}=\frac{3 \chi^{(3)}}{4 \varepsilon_{0} c n_{0}^{2}}$ and,

Laser intensity $I=\frac{1}{2} \varepsilon_{0} c n_{0}|E|^{2}$

Due to intensity dependent value of $n_{2}$ the propagation of fs laser beam through the dielectric gives birth to nonlinear phenomena. The intense laser pulse enhances $n_{2} I$ that plays a significant role to the refractive index $\mathrm{n}$ of the material, leading to self-focusing effect can be expressed as according to critical power for self-focusing:

$P_{c r}=\frac{3.77 \lambda^{2}}{8 \pi n_{0} n_{2}}$ 
Typically, in fused silica, the critical power is $\sim 1.9 \mathrm{MW}$ for the laser wavelength $\lambda=800 \mathrm{~nm}, n_{0}$ $=1.45$ and $n_{2}=3.5 \times 10^{-20} \mathrm{~m}^{2} / \mathrm{W}$. Meanwhile, for this experiment, the critical power can be calculated as $3.14 \mathrm{MW}$ for the laser wavelength $\lambda=1031 \mathrm{~nm}$. Which is much smaller than the intensity for optical breakdown $\left(\sim 10^{13} \mathrm{~W} / \mathrm{cm}^{2}\right)$.
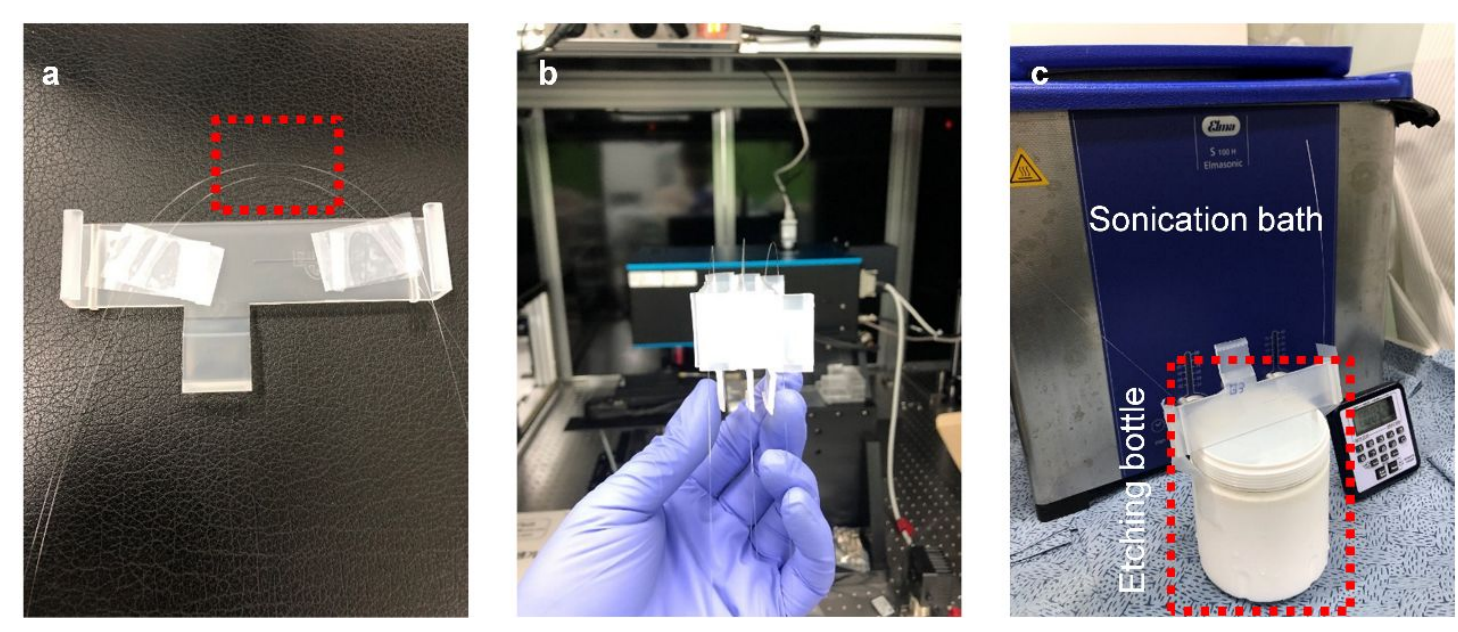

Figure S4. (a) The laser modified region in the fiber (marked with red square) is attached to customized jig to make the fiber stable. (b) Several laser modified fiber loaded for batch processing. (c) Fibers are dipped inside the HF acid solution filled etching bottle to be placed inside sonication bath. 


\section{Graphene growth mechanism on to micro-hole device by ACS method.}

At elevated temperature, the reactive sites $\left(\mathrm{Al}_{\mathrm{III}}\right)$ of $\gamma-\mathrm{Al}_{2} \mathrm{O}_{3}$ catalyst evolve and decrease the dissociation barrier of precursor atoms. The $\mathrm{CH}_{4}$ gas was injected into the furnace as precursor gas. The $\mathrm{CH}_{4}$ gas atoms are decomposed into $\mathrm{C}$ adatoms at the catalytic sites by dissociative adsorption. ${ }^{1,2} \mathrm{With}$ the catalytic activity of $\gamma-\mathrm{Al}_{2} \mathrm{O}_{3}$, more $\mathrm{C}$ adatoms are generated. ${ }^{3}$ According to Arrhenius Equation, the rate of adatom generation can be explain by: ${ }^{4}$

$R=\frac{p_{C H_{4}}}{\sqrt{2 m_{C H_{4}} k T}} S_{0} \exp \left(\frac{-E_{a d}}{k T}\right)$

Where, $E_{a d}=$ Activation energy of adatom generation .

The $\mathrm{C}$ adatoms are continuously generated on the $\gamma-\mathrm{Al}_{2} \mathrm{O}_{3}$ catalyst surface; therefore, density of $\mathrm{C}$ atoms is increased. This phenomenon develops the gradient of concentration of $\mathrm{C}$ atoms, which helps to develop concentration gradient of $\mathrm{C}$ atoms. Saturation density for $\gamma-\mathrm{Al}_{2} \mathrm{O}_{3}$ catalyst can be adopted as follows:

$N_{S}=\left(\frac{C N_{0}{ }^{2}}{\beta q_{0} v}\right)^{1 / 3} R^{1 / 3} \exp \left(\frac{E_{d}}{3 k T}\right)$

Where, $E_{d}=$ Activation energy for surface diffusion.

The generated flux of carbon atoms travels from high concentrated surface to the low concentrated one according to Fick's law of diffusion. Continuing this consideration and neglecting any effects of non-linearity, the spatial diffusion can be addressed with Fick's first law of diffusion as following.., 6 
$j=-D \frac{\partial c}{\partial x}$

Here, D is referred to coefficient of diffusion and $c$ stands for concentration gradience towards a given direction $x$. The Equation S6 illustrates how concentration gradience relates to distance.

The spatially diffused atoms are then anchored onto favorable sites of target surface and Gf nuclei are created consequently. Additional $\mathrm{C}$ adatoms may come into contact with the nuclei to form linear and ring shaped carbon clusters. At the very beginning a few nuclei are formed with low surface coverage, however, the semiconducting properties of graphene as well as higher coverage can thereby be changed with higher growth time. Nucleation rate in spontaneous growth condition for $\gamma-\mathrm{Al}_{2} \mathrm{O}_{3}$ catalyst as follows:

$J=\left(\frac{C}{N_{0} v}\right) R^{2} \exp \left(\frac{2 E_{a}-E_{d}}{k T}\right)$

Where,

$E_{a}=$ Binding energy of an adatom to an adsorption site.

$E_{d}=$ Activation energy for surface diffusion.

It is worth to mention that, the uniform deposition on a substrate requires minimized distance from the source to the target. ${ }^{7}$ 

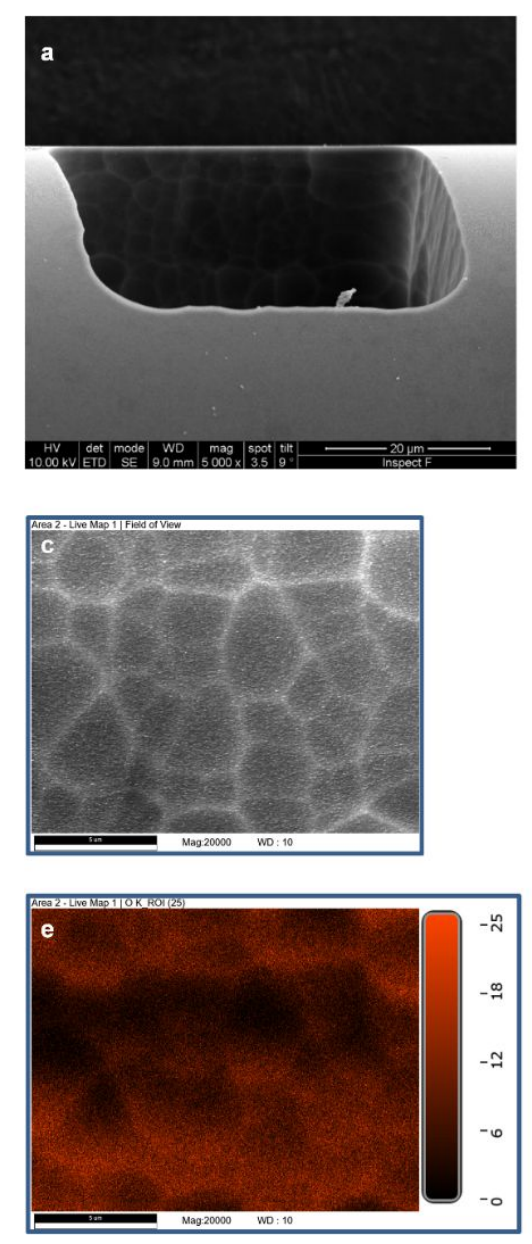
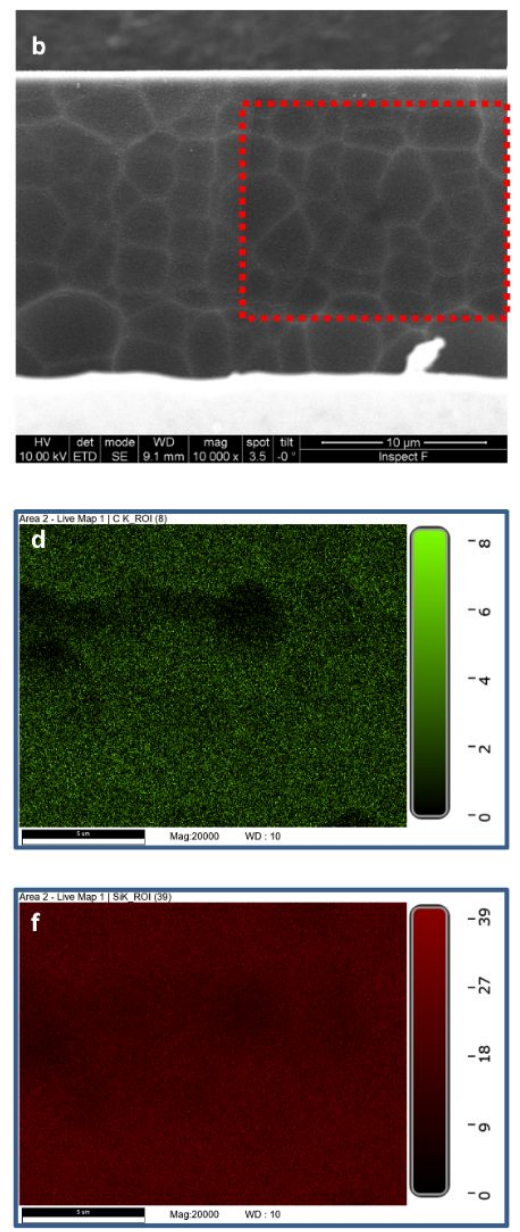

Figure S5. (a) SEM image showing the fabricated 3D microstructure on the optical fiber. (b) Magnified SEM image from the surface of the microstructure. The 3D microstructure was fabricated by femtosecond laser-induced selective etching (FLSE) process followed by chemical etching with $20 \%$ HF solution. The patterns on surface of the microstructure are resulted from the laser modification and chemical etching process (c) SEM image of magnified and selected region from (b) taken for elemental mapping. EDS elemental analyses of the selected region confirm the existence of (d) C, (e) O and (f) Si. The EDS map of C substantiated that the synthesized Gf by ACS method is homogenous and highly covered. 

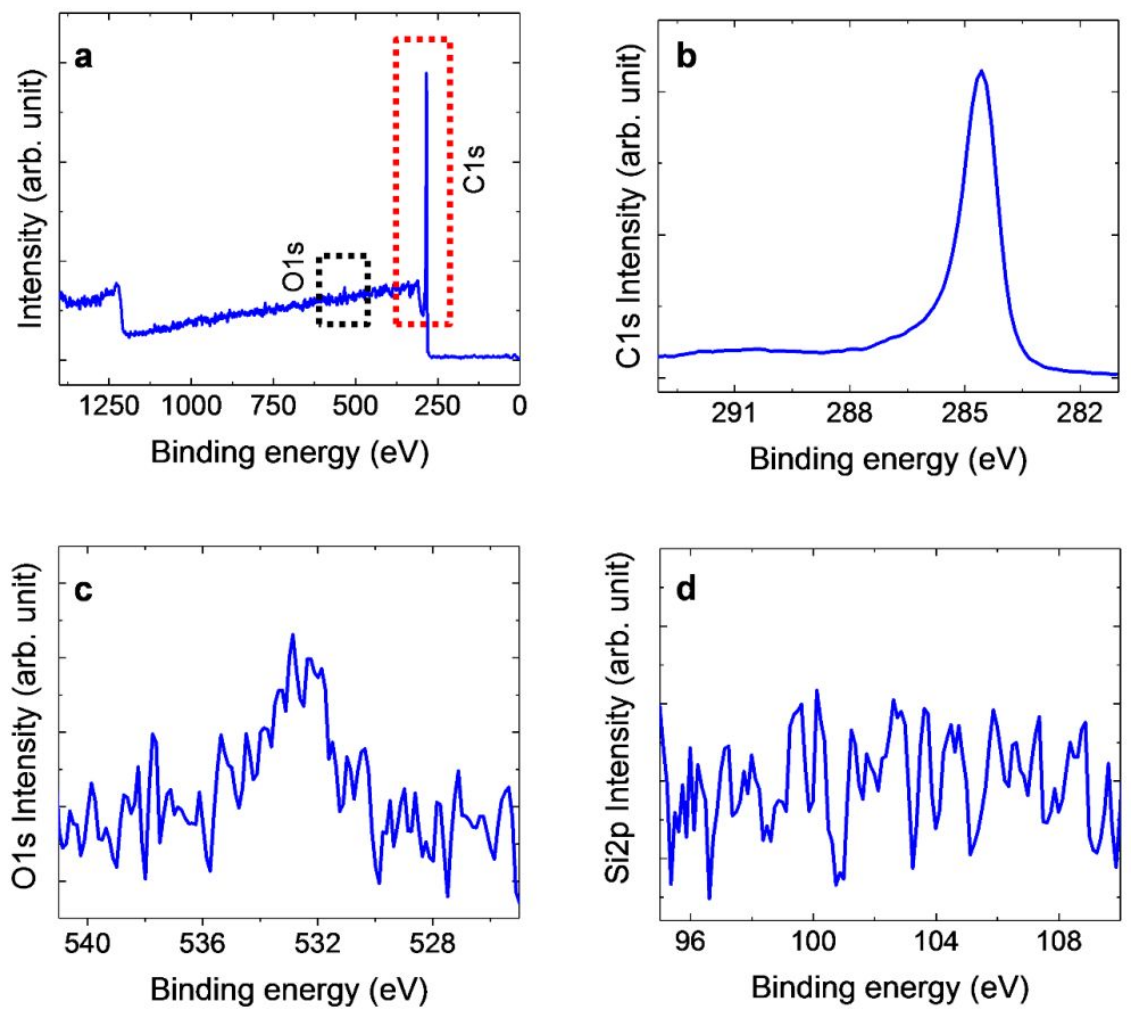

Figure S6. (a) XPS survey spectrum acquired from ACS-grown Gf coated microstructure on the optical fiber. The ratio of $\mathrm{C}: \mathrm{O}$ was determined 1:0.06 from the survey spectrum. Intensity profiles of (b) C1s (c) O1s (d) Si2p from XPS survey study taken from ACS-grown Gf coated microstructure on the optical fiber. 

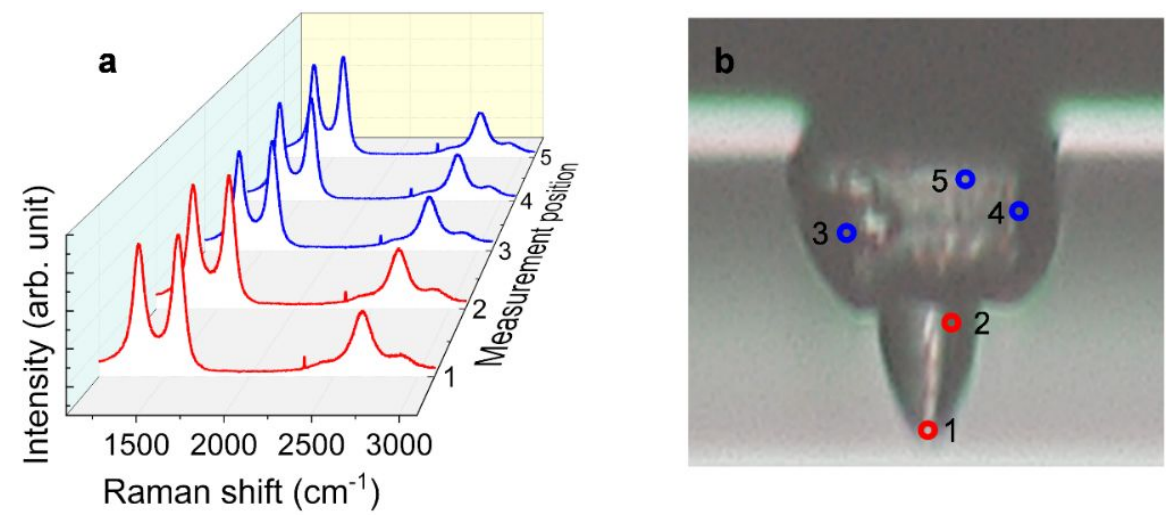

Figure S7. (a) Raman spectra taken from different positions of ACS Gf coated in-fiber microstructure. Presence of analogous characteristic peaks in Raman spectra at different points confirms the successful formation of conformal Gf. (b) Micrograph of ACS Gf coated in-fiber microstructure pointed with colors notifying the data acquiring position.

a

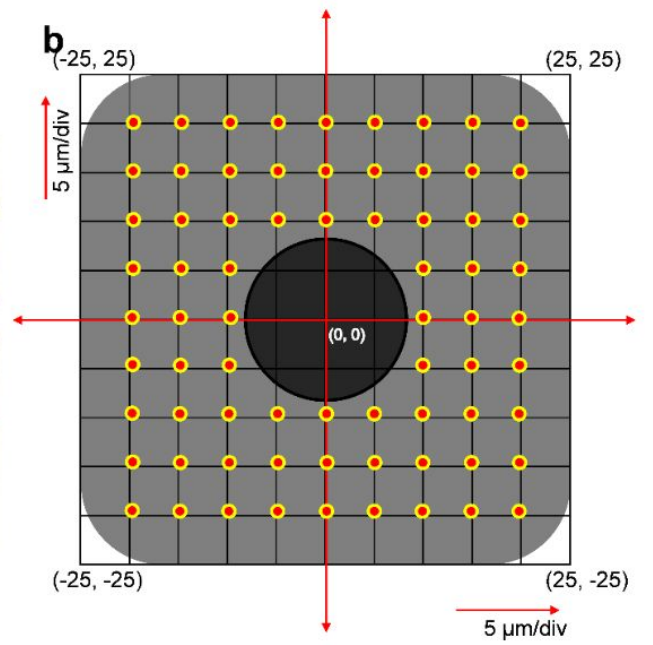

Figure S8. (a) Optical micrograph of the in-fiber microstructure (mentioned with red dotted square). (b) Geometry of measurement for Raman spectroscopy on the in-fiber microstructure. 

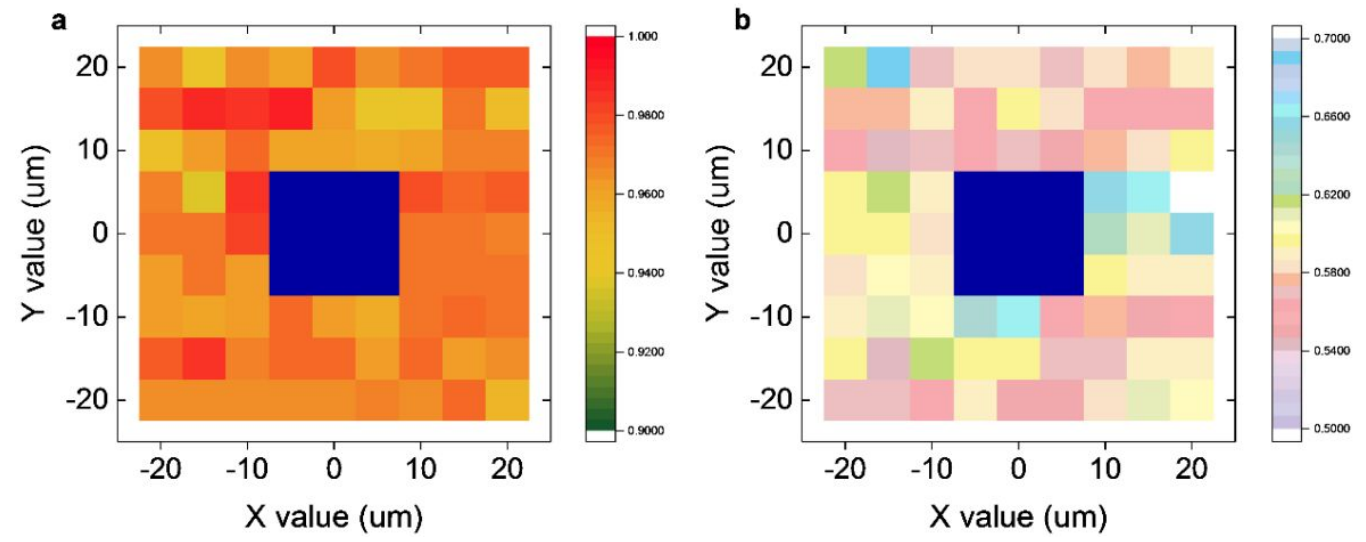

Figure S9. Spatial analysis of Raman intensity ratio map (a) $I_{D} / I_{G}$ (b) $I_{2 D} / I_{G}$. The maps were acquired from the in-fiber micro cavity.
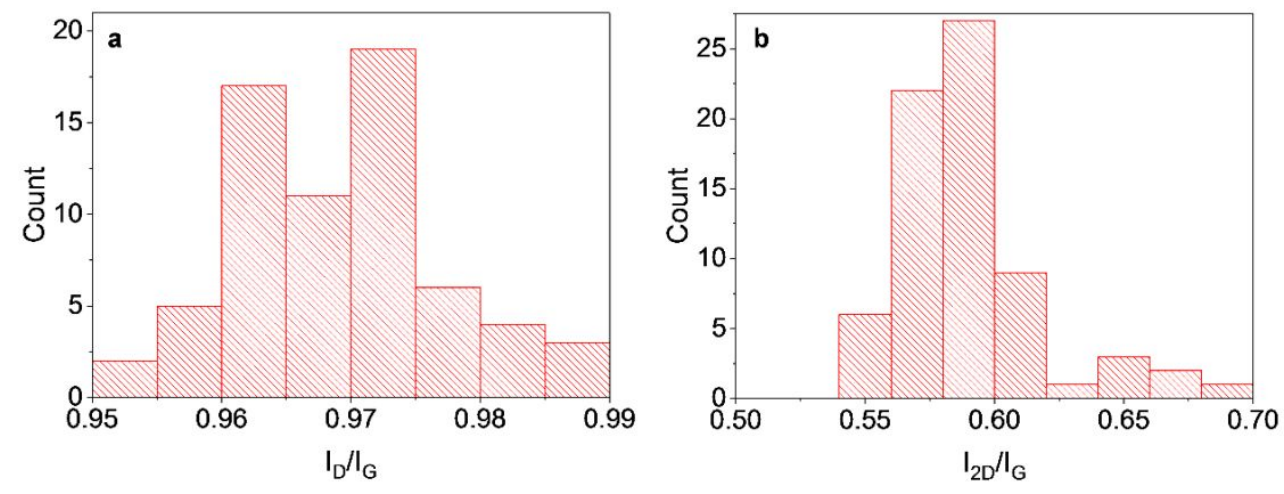

Figure S10. Statistical analysis of Raman intensity ratio of characteristic peaks (a) $\mathrm{I}_{\mathrm{D}} / \mathrm{I}_{\mathrm{G}}(\mathrm{b}) \mathrm{I}_{2 \mathrm{D}} / \mathrm{I}_{\mathrm{G}}$. The measurements were acquired from the in-fiber micro cavity. 

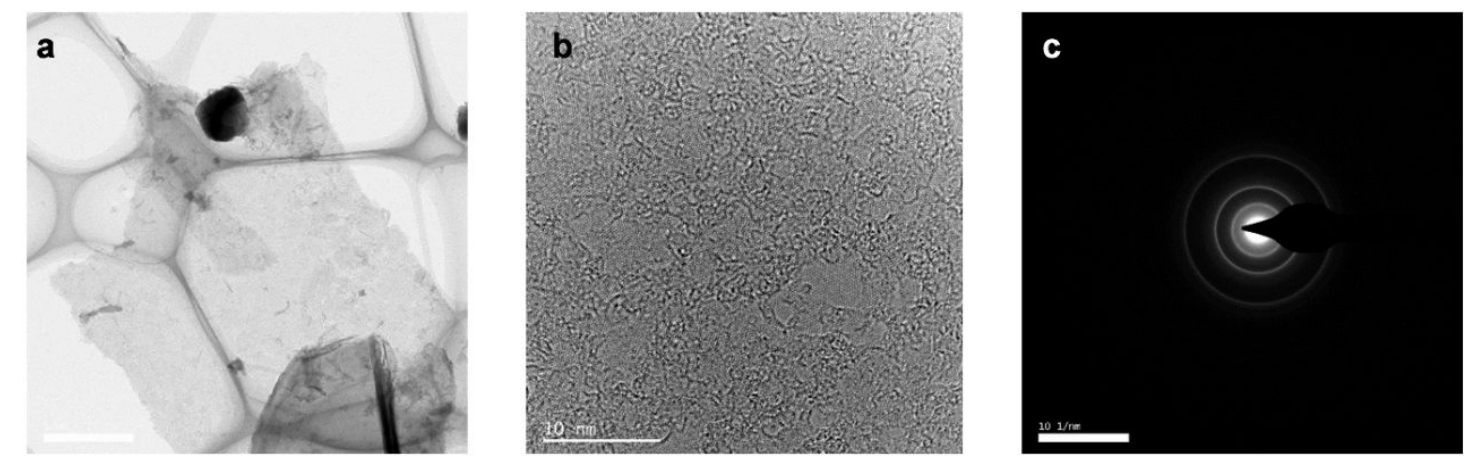

Figure S11. (a) TEM image of Gf film extracted mechanically from the surface of the fiber (scale bar in inset is $10 \mathrm{~nm}$ ). (e) HRTEM image of Gf film (scale bar in inset is $10 \mathrm{~nm}$ ). (c) SAED pattern of HRTEM image in (b) showing two continuous rings. Randomized distribution of Gf nanograins contribute for the continuous rings. 


\section{Nonlinearity measurements:}

The nonlinear absorbtion of the ACS Gf incorporated SA device has been measured with a pulsed laser for the light source, variable optical attenuator for controlling the input power, polarization controller for optimizing the state of polarization, and two power meters to measure the original power of the laser and the power transmitted through the sample. The schematic is shown in Figure S10. The pulse input characteristics are as following: central wavelength, pulse duration, and repetition rate of $1550 \mathrm{~nm}, 110 \mathrm{fs}$, and $100 \mathrm{MHz}$, respectively.

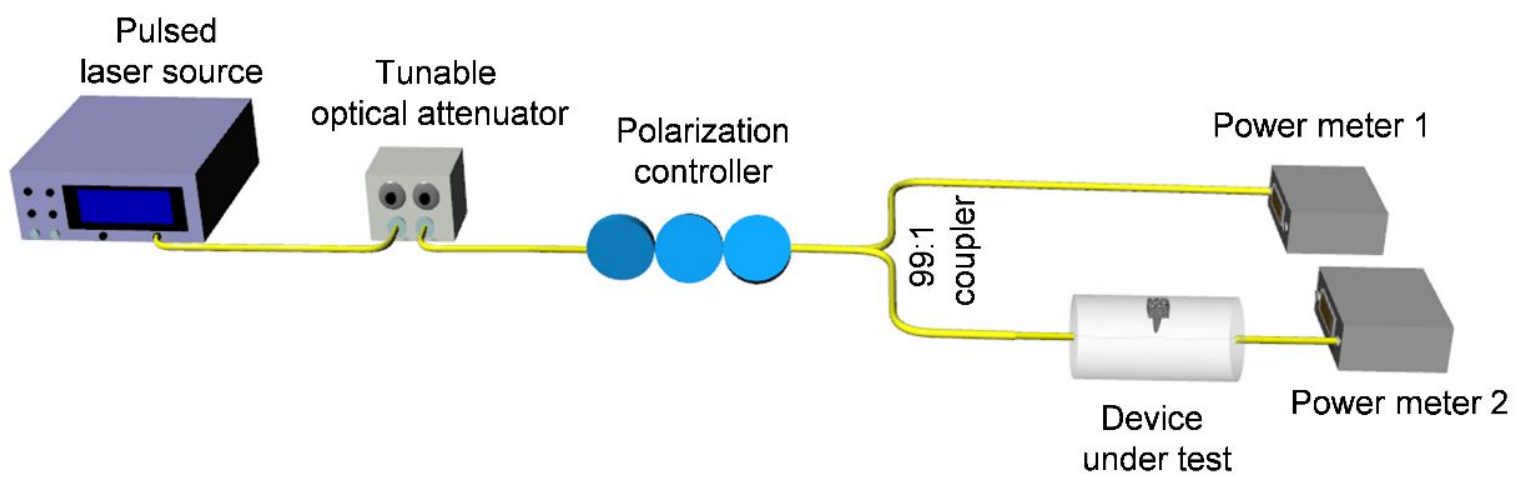

Figure S12. Schematic of the optical nonlinearity test setup used in the experiment.

From the fitting curve the non-saturable loss, saturation intensity and modulation depth were found to be $17.3 \%, 4.37 \mathrm{~mW}$ and $0.875 \%$ respectively, which was a result of nonlinear optical absorption of the ACS Gf. 

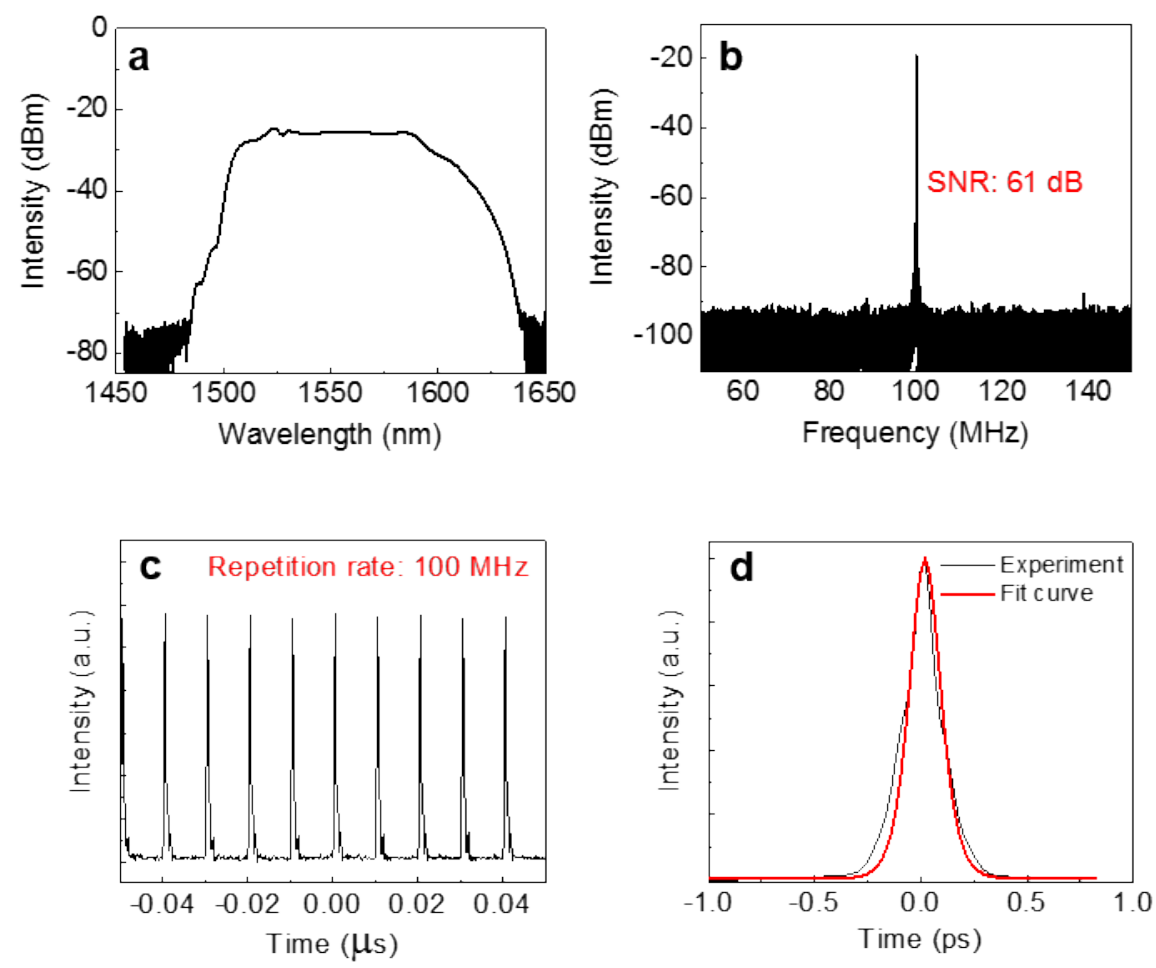

Figure S13. The input pulse characteristics for measurement of nonlinearity. (a) The optical spectrum of the generated pulse. (b) RF spectrum of the pulse with SNR of $61 \mathrm{~dB}$. (c) The generated pulse train with the repetition rate of $100 \mathrm{MHz}$. (d) The auto-correlation data of the pulse that shows the pulse duration of $110 \mathrm{fs}$. 


\section{Confinement of intracavity power}

A mode locking condition in laser comprises self-organization of photons in short time-scale, which means a stable synchronization of pulses through nonlinear interaction. According to nonlinear Schrodinger equation, the pulse propagation in the fiber cavity can be explained as:

$\frac{\partial \mathrm{A}}{\partial \mathrm{z}}=-\frac{\alpha_{\text {loss }}}{2} A-\beta_{1} \frac{\partial A}{\partial t}-\frac{i}{2} \beta_{2} \frac{\partial^{2} A}{\partial t^{2}}+\frac{1}{6} \beta_{3} \frac{\partial^{3} A}{\partial t^{3}}+i \gamma|A|^{2} A$

For mode-locked pulses, Equation S8 can be rewritten according to Haus's master equation for mode locked pulses:

$\frac{1 \partial}{T_{R} \partial \mathrm{T}} a=(g-l) a+\frac{g \partial^{2}}{\Omega_{g}^{2} \partial \mathrm{t}^{2}} a+\gamma|a|^{2} \mathrm{a}$

Where,

$T_{R}=$ cavity roundtrip time.

$g-l=$ net gain of cavity

$\Omega_{f}=$ modulation frequency

$D=$ group velocity dispersion $(\mathrm{GVD})$

$\gamma=$ self amplitude modulation coefficient

$\delta=$ the Kerr-coefficient

$a=$ pulse amplitude 
Here minimum loss lead to more longitudinal mode loss simultaneously in phase yielding short pulses with high pulse energy.

In this laser cavity built for this experiment, the SA was fabricated by processing minimal loss. After fabricating the in-fiber microstructure (IFM), the loss was $0.5 \mathrm{~dB}$ which increased to $1.4 \mathrm{~dB}$ after synthesis of Gf by ACS process. In this way, maximizing the gain was realized by minimizing the device fabrication loss. Therefore, high pulse energy can be extracted from the fiber laser cavity by minimizing cavity loss.

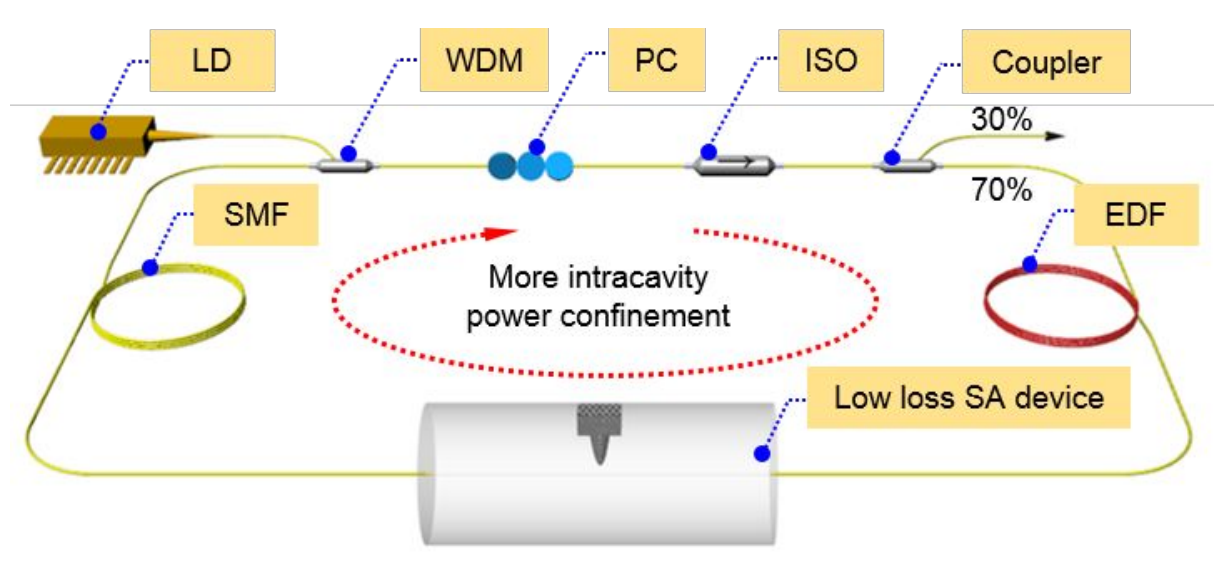

Figure S14. Schematic of laser cavity explaining high-energy pulse extraction by confining more intracavity power in the cavity with low-loss SA device. 


\section{Evolution of Peak Power.}

The mode-locking operation was noticeable when the intracavity power was ranging between 58.7$82.6 \mathrm{~mW}$. Beyond these values, there was no observable mode-locking. The trend of peak power increased with the increment of intracavity power. With following equation, we calculated peak power.

$P_{\text {peak }}=\frac{P_{\text {avg }}}{f_{\text {rep }} \tau}=\frac{P_{\text {avg }}}{\text { Duty cycle }}=20.3 \mathrm{~kW}$

Table S1. Trend peak power as functions of intracavity power.

\begin{tabular}{|c|c|c|c|c|c|}
\hline Intracavity power & Average power & Repetition rate & Pulse width & Pulse energy & Peak power \\
\hline $58.68534 \mathrm{~mW}$ & $17.6056 \mathrm{~mW}$ & $1.86 \mathrm{MHz}$ & $650 \mathrm{fs}$ & $9.46299 \mathrm{~nJ}$ & $14.34 \mathrm{~kW}$ \\
\hline $63.30767 \mathrm{~mW}$ & $18.9923 \mathrm{~mW}$ & $1.86 \mathrm{MHz}$ & $650 \mathrm{fs}$ & $10.2083 \mathrm{~nJ}$ & $15.47 \mathrm{~kW}$ \\
\hline $67.059 \mathrm{~mW}$ & $20.1177 \mathrm{~mW}$ & $1.86 \mathrm{MHz}$ & $650 \mathrm{fs}$ & $10.8132 \mathrm{~nJ}$ & $16.64 \mathrm{~kW}$ \\
\hline $70.44899 \mathrm{~mW}$ & $21.1347 \mathrm{~mW}$ & $1.86 \mathrm{MHz}$ & $650 \mathrm{fs}$ & $11.3599 \mathrm{~nJ}$ & $17.48 \mathrm{~kW}$ \\
\hline $73.16539 \mathrm{~mW}$ & $21.94962 \mathrm{~mW}$ & $1.86 \mathrm{MHz}$ & $650 \mathrm{fs}$ & $11.7979 \mathrm{~nJ}$ & $18.15 \mathrm{~kW}$ \\
\hline $75.50097 \mathrm{~mW}$ & $22.65029 \mathrm{~mW}$ & $1.86 \mathrm{MHz}$ & $650 \mathrm{fs}$ & $12.1745 \mathrm{~nJ}$ & $18.73 \mathrm{~kW}$ \\
\hline $77.61208 \mathrm{~mW}$ & $23.28363 \mathrm{~mW}$ & $1.86 \mathrm{MHz}$ & $650 \mathrm{fs}$ & $12.5149 \mathrm{~nJ}$ & $19.25 \mathrm{~kW}$ \\
\hline $79.35435 \mathrm{~mW}$ & $23.80631 \mathrm{~mW}$ & $1.86 \mathrm{MHz}$ & $650 \mathrm{fs}$ & $12.7959 \mathrm{~nJ}$ & $19.99 \mathrm{~kW}$ \\
\hline $81.15098 \mathrm{~mW}$ & $24.34529 \mathrm{~mW}$ & $1.86 \mathrm{MHz}$ & $650 \mathrm{fs}$ & $13.0856 \mathrm{~nJ}$ & $20.45 \mathrm{~kW}$ \\
\hline $82.55296 \mathrm{~mW}$ & $24.76589 \mathrm{~mW}$ & $1.86 \mathrm{MHz}$ & $650 \mathrm{fs}$ & $13.3116 \mathrm{~nJ}$ & $20.8 \mathrm{~kW}$ \\
\hline
\end{tabular}




\section{Comparison of Peak Power.}

Table S2. Comparison of peak power of mode-locked pulses from Gf incorporated fiber laser.

\begin{tabular}{|c|c|c|c|c|c|}
\hline Ref. & Material & $\begin{array}{l}\text { Avg. power } \\
\text { (mW) }\end{array}$ & $\begin{array}{l}\text { Pulse width } \\
\text { (ps) }\end{array}$ & $\begin{array}{l}\text { Pulse energy } \\
\text { (nJ) }\end{array}$ & $\begin{array}{c}\text { Peak power } \\
(\mathrm{kW})\end{array}$ \\
\hline$[8]$ & Graphene- $-\mathrm{Bi}_{2} \mathrm{Te}_{3}$ & 3.07 & 0.837 & 0.178 & 0.21266 \\
\hline$[9]$ & graphene- $\mathrm{Mo}_{2} \mathrm{C}$ & 10.93 & 0.723 & 0.713 & 0.98617 \\
\hline$[10]$ & Graphene & 3 & 1.230 & 1.18 & 0.95935 \\
\hline [11] & Graphene-PVDF & 20.42 & 0.694 & 3 & 4.32277 \\
\hline$[12]$ & Graphene & 2 & 1.170 & 1.12 & 0.95726 \\
\hline [13] & Graphene- $-\mathrm{Bi}_{2} \mathrm{Te}_{3}$ & 2 & 1.290 & 0.27 & 0.2093 \\
\hline [14] & GO & 0.95 & 0.657 & 0.04036 & 0.06143 \\
\hline [15] & Graphene & 1.78 & 2.962 & 0.5 & 0.1688 \\
\hline$[15]$ & Graphene & 1.34 & 2.580 & 0.37 & 0.14341 \\
\hline [16] & Graphene-PVDF & 0.67 & 2.920 & 0.41 & 0.14041 \\
\hline [17] & Graphene-PVA & 1 & 1.000 & 0.125 & 0.125 \\
\hline [18] & $\begin{array}{l}\text { Graphene- } \\
\text { composite }\end{array}$ & 1.2 & 0.174 & 0.044 & 0.25287 \\
\hline [19] & Graphene & 2 & 3.6 & 0.4 & 0.11111 \\
\hline [20] & Graphene & 2.1 & 13 & 0.04 & 0.03077 \\
\hline [21] & Graphene-DMF & 15.85 & 0.850 & 3 & 3.52941 \\
\hline$[22]$ & Graphene & 0.6 & 0.900 & 0.005 & 0.00556 \\
\hline
\end{tabular}




\begin{tabular}{|c|c|c|c|c|c|}
\hline [23] & Graphene & 2.8 & 0.570 & 0.0246 & 0.04316 \\
\hline [24] & Graphene & 30 & 0.844 & 1.84 & 2.18009 \\
\hline [25] & Graphene & 4 & 0.630 & 0.1 & 0.15873 \\
\hline [26] & Graphene & 1 & 0.430 & 0.02 & 0.04651 \\
\hline [26] & Graphene & 1.02 & 0.810 & 20 & 24.69136 \\
\hline [27] & Graphene & 1 & 0.570 & 0.0228 & 0.04 \\
\hline [28] & $\begin{array}{c}\text { Graphene/Chitosan } \\
\text { solution }\end{array}$ & 3.5 & 0.168 & 0.055 & 0.32738 \\
\hline [29] & $\begin{array}{l}\text { Graphene/PMMA } \\
\text { composite }\end{array}$ & 1.5 & 0.088 & 0.071 & 0.80682 \\
\hline [30] & Graphene & 5.1 & 0.312 & 0.06 & 0.19231 \\
\hline [31] & $\begin{array}{c}\text { Graphene/Chitosan } \\
\text { solution }\end{array}$ & 2.13 & 0.224 & 0.047 & 0.20982 \\
\hline [31] & $\begin{array}{c}\text { Graphene/Chitosan } \\
\text { solution }\end{array}$ & 120 & 0.027 & 2.66 & 98.51852 \\
\hline [31] & $\begin{array}{c}\text { Graphene/Chitosan } \\
\text { solution }\end{array}$ & 135 & 0.024 & 3 & 125 \\
\hline $\begin{array}{l}\text { This } \\
\text { work }\end{array}$ & Graphene & 24.76589 & 0.640 & 13.3116 & 20.8 \\
\hline
\end{tabular}



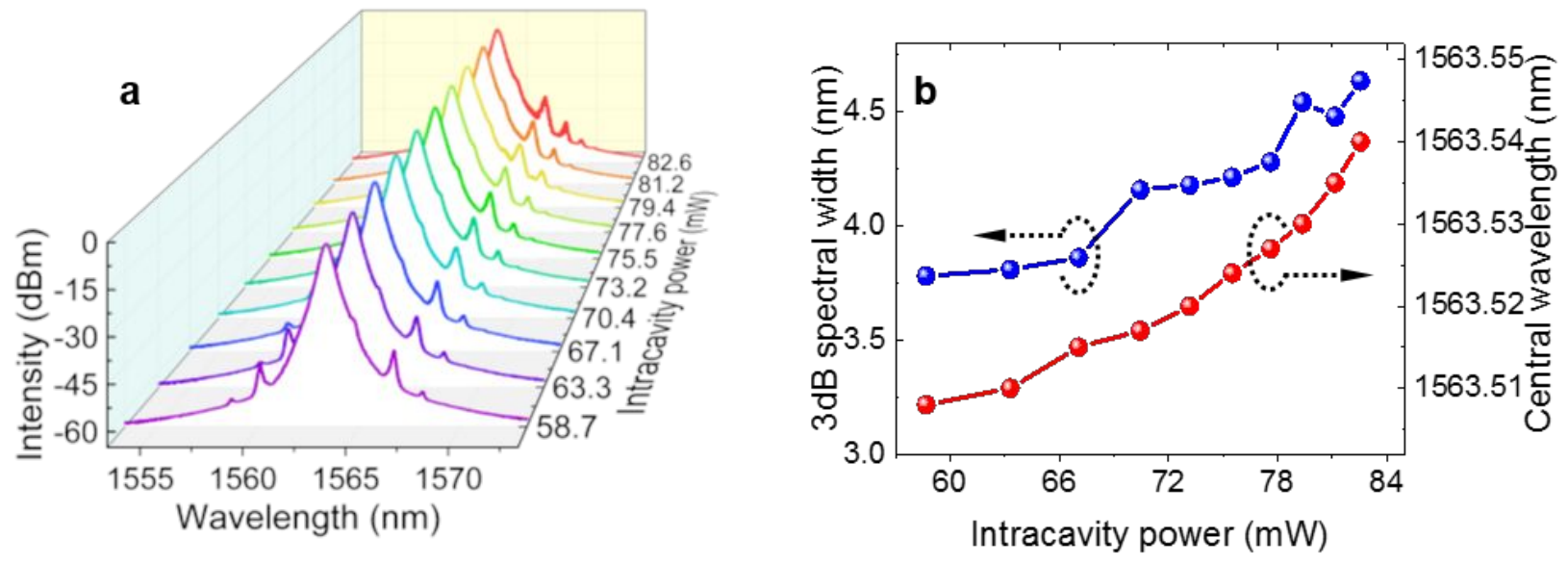

Figure S15. (a) Optical spectra as a function of incremental intracavity optical power acquired from of the passively mode-locked fiber laser based on ACS Gf-coated micro-hole SA device. No pulse breaking was found within the intracavity power range of 58.7 to $82.6 \mathrm{~mW}$. (b) Plot of $3 \mathrm{~dB}$ spectral width (blue curve) and central wavelength (red curve) of output solitonic pulses as a function of incremental intracavity optical power.
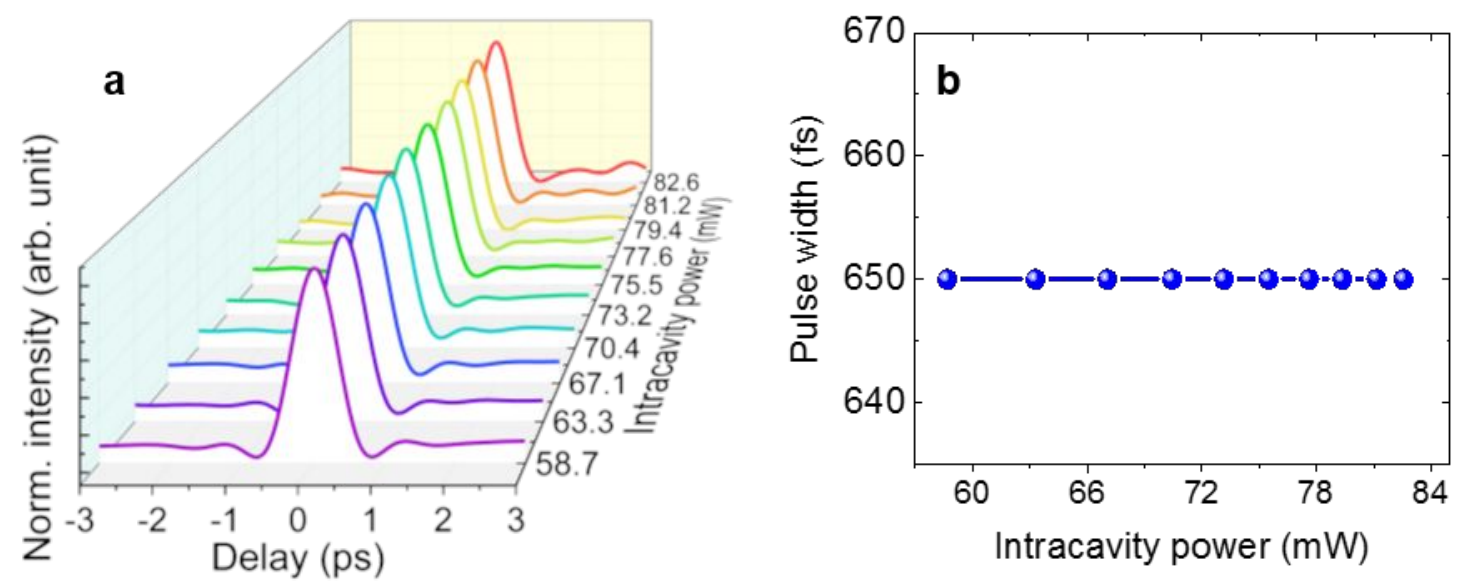

Figure S16. (a) Autocorrelation traces as a function of incremental intracavity optical power acquired from of the passively mode-locked fiber laser based on ACS Gf-coated micro-hole SA device. (b) Plot of pulse width coresponding to the output solitonic pulses as a function of 
incremental intracavity optical power. No pulse breaking was found within the intracavity power range of 58.7 to $82.6 \mathrm{~mW}$.
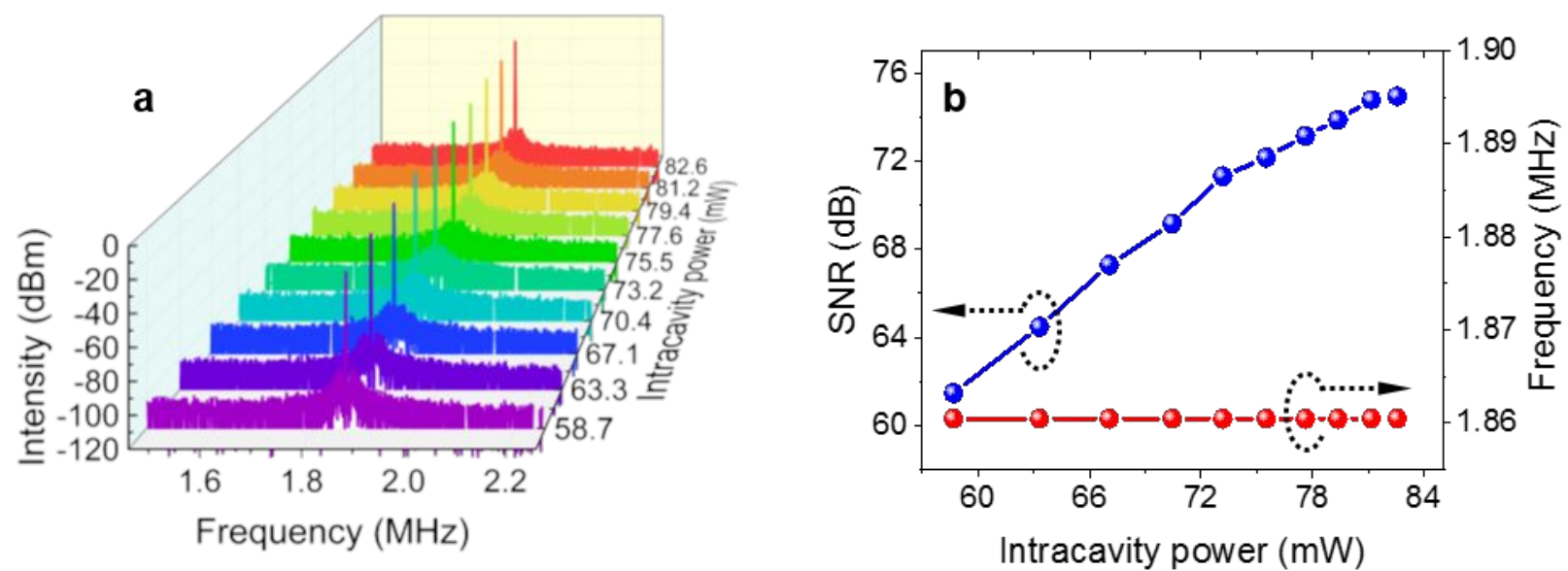

Figure S17. (a) RF spectra as a function of incremental intracavity optical power acquired from of the passively mode-locked fiber laser based on ACS Gf-coated micro-hole SA device. Incremental trend of SNR was found for the incremental intracavity power ranging from 58.7 to $82.6 \mathrm{~mW}$. (b) Plot of signal to noise ratio (blue curve) and frequency (red curve) corresponding to the output solitonic pulses as a function of incremental intracavity optical power. 


\section{Stability of the laser}

The long-term stability performance of the mode-locked laser is important for practical applications, which has been verified under the ambient condition in this work. In order to investigate stability operation, as shown in Figure S18, the output characteristics of the fiber laser were monitored continuously at intervals of 30 mins over a period of 2 hours per day for 1 week. During the measurement period, 3-dB spectrum width and central wavelength were taken into account at an adjusted intracavity power of $67.1 \mathrm{~mW}$. It can be seen from the red curve in Figure S18 that, a negligible shift of the central wavelength was recorded as it fluctuated within 1563.44 $\mathrm{nm}$ to $1563.45 \mathrm{~nm}$ implying a mere SD of $0.55 \%$ during the stability experiment.

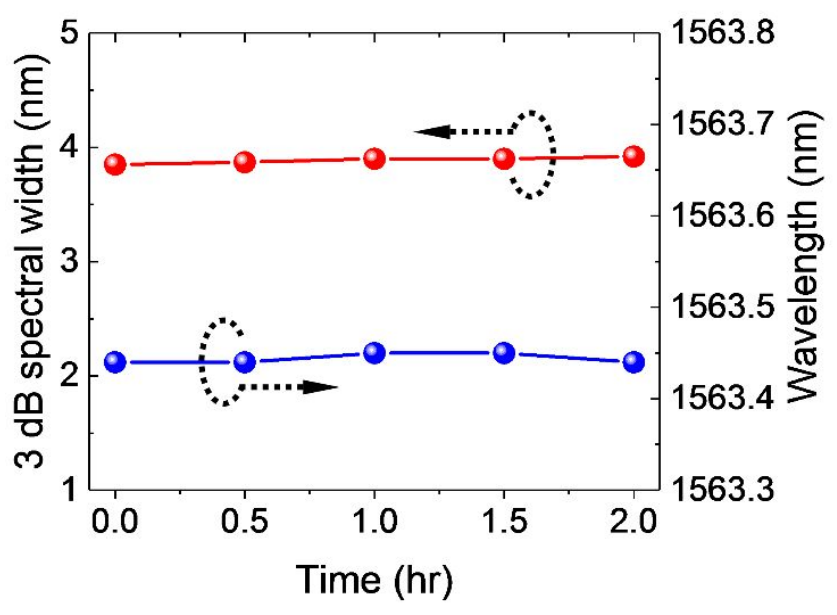

Figure S18. Stability test of the mode-locked laser showing negligible drift of the spectral bandwidth and the central wavelength over the long time duration. 


\section{Photon energy and bandwidth}

The photon energy of pulse can be computed from its wavelength $\lambda$, frequency $v$. The photon energy is:

$E_{p}=h v=h \frac{c}{\lambda}$

Where, $h=6.626 \times 10^{-34}$ is the Planck constant and $c$ is the speed of light in vacuum.

$E_{p}=1.2706 e^{-19} \mathrm{~J}=793.04 \mathrm{meV}$. The photon energy of pulse is $793.04 \mathrm{meV}$.

The frequency bandwidth can be directly calculated as following for intracavity power of 41.02 $\mathrm{mW}$.

$\Delta v=v_{\text {stop }}-v_{\text {start }}=473 \mathrm{GHz}$

The center frequency $v_{o}=\frac{c}{\lambda_{o}}=191.751 \mathrm{THz}$ 


\section{Selection of the microstructure}

Since the nonlinear interaction is inversely proportional to the distance between the nanomaterials and the fiber core, Gf at the tip plays major role in the mode-locking when we coat the surface of the microstructure surface with Gf. However, importantly, Gf located near the tip also can be covered by the evanescent field and involved to the nonlinear interaction as well as both linear and nonlinear optical absorptions. In order to control the interaction under this situation, we should consider many parameters including the interaction length and width, material distribution, surface condition of the microstructure, and Gf crystallinity that contribute to the trade-off between the nonlinear interaction and optical loss.

our approach suggested in this work can provide a precision control on the optical loss-correlated nonlinear interaction overcoming the drawbacks displayed in the conventional methods. The design (both positioning and shaping) of the microstructure is extremely important in terms of (1) the nonlinear interaction control with the parameters of tip-core distance and interaction length, (2) spatial diffusion of carbon atoms to form Gf near the deep tip area, and (3) smooth surface condition of the microstructure guarantees the uniform nucleation and growth of Gf crystals that suppressing the optical loss while maintaining the targeted nonlinear interaction. Finally, we realized the microstructure by laser-fabricating process with very high process efficiency and precision control, along with the uniform Gf coating by our novel ACS Gf growth, which cannot be achieved by the conventionally transferred Gf. 


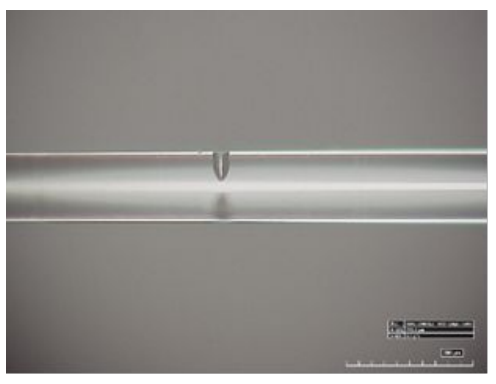

(a)

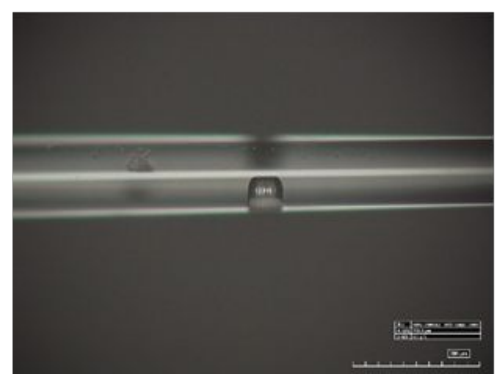

(b)

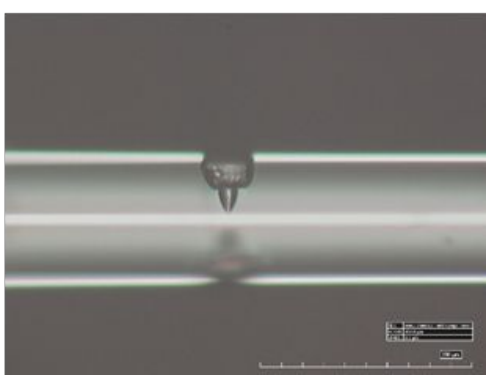

(c)

Figure S19. Individual microstructures of (a) hole, (b) cavity, and (c) cavity + hole.

We have tested hole, cavity and cavity+hole structures separately to compare the optical properties as well as the fabrication process efficiency of Gf synthesized onto the inner surfaces of the structures. In case of the hole structure, it was difficult to form the uniform Gf coating because of the spatial/surface diffusion problem of carbon atoms. With the single cavity structure, we achieved a successful mode-locking as we expected, but the loss was very high as well. Finally, we found a very good balance among the nonlinearity, optical loss and Gf synthesis in the cavity+hole 2-step structure, which is vital to the high-energy pulse generation. Since the conventional fabrication processes including the mechanical and chemical processes cannot provide the precision-controlled microstructure, we employed the femtosecond laser-induced selective etching (FLSE) process. Significance of the cavity+hole structure was summarized in Table 1, the advantages have been provided in the manuscript.

Table S3. Comparison of the microstructures

\begin{tabular}{|c|c|c|c|c|c|}
\hline Parameters & Parameter 1 & Parameter 2 & Parameter 3 & Parameter 4 & Parameter 5 \\
\hline Hole & Low & Low & Low & High & Fair \\
\hline Cavity & High & Very high & Fair & Low & High \\
\hline Cavity+hole & High & High & High & Low & Low \\
\hline
\end{tabular}


- Parameter 1: Degree of freedom for the depth control of the micrstructure.

- Parameter 2: Accessibility for both etchant and carbon atoms to the tip area of the microstructure.

- Parameter 3: Surface smoothness of the tip area.

- Parameter 4: Sample loss during the fabrication.

- Parameter 5: Optical transmission loss. 


\section{Selection of the dispersion regime}

It is possible to generate high-energy pulses by operating the fiber lasers at normal dispersion regime as the net GVD as well as the excessive nonlinear effect can be minimized in normal dispersion operational condition. ${ }^{32-34}$ However, in the regime, although conventional SAs used in anomalous dispersion regime such as semiconductor SA mirrors, ${ }^{35}$ carbon nanotubes, ${ }^{36} \mathrm{Gf},{ }^{37}$ etc. are employed, the pulse duration gets wider and pulse energy becomes lower over operational time. ${ }^{38-41}$ Meanwhile, in anomalous dispersion regime, we all care about the short pulse duration of the phase-locked pulses that will increase the peak power.

Here, from the literatures, we compared the pulse characteristics of Gf SA-based lasers operating at normal dispersion regime and anomalous dispersion regime.

Table S4. Gf or Gf derivative-based SAs for lasing in NORMAL dispersion regime.

\begin{tabular}{|c|c|c|c|c|c|c|}
\hline Dispersion & Material & $\begin{array}{c}\text { Avg. power } \\
(\mathrm{mW})\end{array}$ & $\begin{array}{c}\text { Pulse width } \\
(\mathrm{ps})\end{array}$ & $\begin{array}{c}\text { Pulse energy } \\
(\mathrm{nJ})\end{array}$ & $\begin{array}{c}\text { Peak power } \\
(\mathrm{W})\end{array}$ & Ref. \\
\hline Normal & Gf & 3.05 & 4230 & 1.713 & 0.405 & 42 \\
\hline Normal & Gf & 13.2 & 6500 & 0.81 & 0.125 & 43 \\
\hline Normal & GO & 147.8 & 60800 & 137.1 & 2.25 & 44 \\
\hline Normal & GO & 2.1 & 340 & 0.148 & 0.435 & 45 \\
\hline
\end{tabular}




\begin{tabular}{|c|c|c|c|c|c|c|}
\hline Normal & Gf & & 38.6 & & & 46 \\
\hline Normal & GO & 3.53 & 74.6 & 6.4 & 85.8 & 47 \\
\hline Normal & GO & 0.19 & 2300 & 0.18 & 0.078 & 48 \\
\hline Normal & GO/PVA & 6 & 1680 & 2.75 & 0.0016 & 49 \\
\hline Normal & GO/PVA & 539 & 1680 & 429 & 25.5 & 49 \\
\hline Normal & GO & & 755 & & & 50 \\
\hline
\end{tabular}

Table S5. Gf or Gf derivative-based SAs for lasing in ANOMALOUS dispersion regime.

\begin{tabular}{|c|c|c|c|c|c|c|}
\hline $\begin{array}{c}\text { Dispersion } \\
\text { Regime }\end{array}$ & Material & $\begin{array}{l}\text { Avg. power } \\
(\mathrm{mW})\end{array}$ & $\begin{array}{c}\text { Pulse } \\
\text { width (ps) }\end{array}$ & $\begin{array}{c}\text { Pulse energy } \\
\text { (nJ) }\end{array}$ & $\begin{array}{c}\text { Peak } \\
\text { power } \\
(\mathrm{kW})\end{array}$ & Ref. \\
\hline Anomalous & $\begin{array}{c}\text { Gf- } \\
\mathrm{Bi}_{2} \mathrm{Te}_{3}\end{array}$ & 3.07 & 0.837 & 0.178 & 0.21266 & 8 \\
\hline Anomalous & $\begin{array}{c}\text { Gf- } \\
\mathrm{Mo}_{2} \mathrm{C}\end{array}$ & 10.93 & 0.723 & 0.713 & 0.98617 & 9 \\
\hline Anomalous & Gf & 3 & 1.230 & 1.18 & 0.95935 & 10 \\
\hline Anomalous & $\begin{array}{c}\text { Gf- } \\
\text { PVDF }\end{array}$ & 20.42 & 0.694 & 3 & 4.32277 & 11 \\
\hline Anomalous & Gf & 2 & 1.170 & 1.12 & 0.95726 & 12 \\
\hline Anomalous & $\begin{array}{c}\text { Gf- } \\
\mathrm{Bi}_{2} \mathrm{Te}_{3}\end{array}$ & 2 & 1.290 & 0.27 & 0.2093 & 13 \\
\hline
\end{tabular}




\begin{tabular}{|l|c|c|c|c|c|c|}
\hline Anomalous & GO & 0.95 & 0.657 & 0.04036 & 0.06143 & 14 \\
\hline Anomalous & Gf & 1.78 & 2.962 & 0.5 & 0.1688 & 15 \\
\hline Anomalous & Gf & 1.34 & 2.580 & 0.37 & 0.14341 & 15 \\
\hline Anomalous & Gf & 24.76589 & 0.640 & 13.3116 & 20.8 & $\begin{array}{c}\text { This } \\
\text { work }\end{array}$ \\
\hline
\end{tabular}

In addition to the aforementioned comparison between the lasing regimes of normal and

anomalous, there are several articles where lasing is demonstrated in both of the regimes with a single SA. ${ }^{51,52}$ The reports highlight the advantages of selecting anomalous regime for generating ultrashort pulses with high peak power that has close correlation with the nonlinear operation of devices. When we go from ps to fs pulse duration, especially in the anomalous dispersion regime, the peak power will dramatically increase even if the pulse energy remains the same. 


\section{Polarization dependent loss of the device}

The fabricated device is polarization dependent (see figure). With the increment of inserted power, the polarization dependent loss (PDL) ranges from 0.1185 to $0.7247 \mathrm{~dB}$ with a standard deviation of $\sim 18 \%$. The minimum and maximum input power to the sample are -3.35 and 14.2 $\mathrm{dBm}$, respectively.

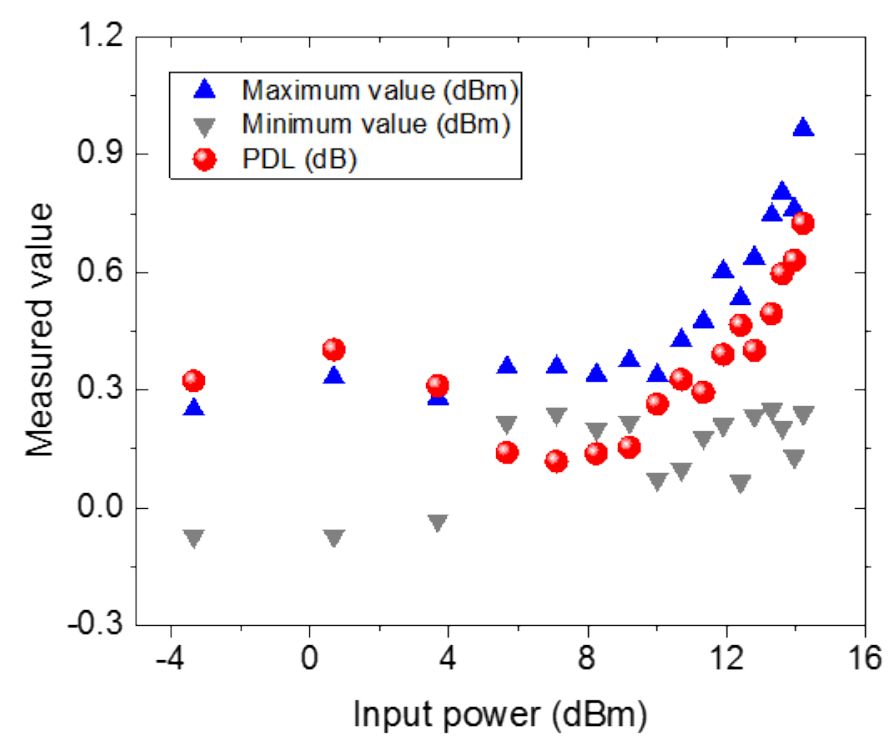

Figure S20. Input power dependent polarization dependent characteristics of the fabricated device.

However, although the device is PDL dependent, the device was set to the optimized state of polarization (SOP) in order to minimize the polarization effect on mode-locking. In the experiment, a PC was employed to optimize the SOP, thereby the system was fixed with the right SOP and mode-locking has been found. 


\section{High-energy pulse generation.}

Mode-locked pulses are from the self-synchronization of sub-modes co-propagating through the nonlinear medium employed in the laser cavity. The laser cavity consists a piece of single mode fiber (SMF), an output coupler that extracts the signal out of the cavity after each round trip, and a bandwidth-limited energy pump that compensates the energy lost during propagation.

When maximum longitudinal modes satisfy the phase matching condition in a short time duration, the minimum loss state is achieved inside the cavity, which can be referred to as maximum intracavity gain. When combined with the laser cavity polarization rotation, bandwidth limited saturating gain, chromatic dispersion, and self-phase modulation, a uniform train of stable modelocked pulses may be formed from white noise after a certain number of round trips. A low-loss SA device, combined with a gain medium, plays an important role in the cavity resulting in minimum intracavity loss; thereby maximum intracavity power is confined within the cavity.

The governing equations for modeling the pulse evolution and the intracavity evolution in the laser can be described by a pair of dimensionless coupled nonlinear Schrodinger equations. However, the fiber lasers have components that cannot be modeled by several phase modulation terms in NLSEs. For example, a fiber laser has a gain with a limited gain bandwidth and a saturable absorber. They do not induce the phase modulation, but they definitely cause the amplitude modulation in the frequency and time domain. To count the amplitude modulation effects in a laser cavity properly, more terms needed to be added to NLSEs. The resulting differential equations are called coupled cubic Ginzburg Landau equations as:

$$
\frac{\partial \mathrm{u}_{x}}{\partial \mathrm{z}}=\frac{(g-\alpha)}{2} \mathrm{u}_{x}+\delta \frac{\partial \mathrm{u}_{x}}{\partial \mathrm{t}}+\left(\frac{g}{2 \Omega_{g}^{2}}-i \frac{\beta_{2}}{2}\right) \frac{\partial^{2} \mathrm{u}_{x}}{\partial t^{2}}+\frac{\beta_{3} \partial^{3} \mathrm{u}_{x}}{6 \partial t^{3}}+i \gamma\left(\left|\mathrm{u}_{x}\right|^{2}+\frac{2}{3}\left|\mathrm{u}_{y}\right|^{2}\right) \mathrm{u}_{x}
$$




$$
\frac{\partial \mathrm{u}_{y}}{\partial \mathrm{z}}=\frac{(g-\alpha)}{2} \mathrm{u}_{y}-\delta \frac{\partial \mathrm{u}_{y}}{\partial \mathrm{t}}+\left(\frac{g}{2 \Omega_{g}^{2}}-i \frac{\beta_{2}}{2}\right) \frac{\partial^{2} \mathrm{u}_{y}}{\partial t^{2}}+\frac{\beta_{3} \partial^{3} \mathrm{u}_{y}}{6 \partial t^{3}}+i \gamma\left(\left|\mathrm{u}_{y}\right|^{2}+\frac{2}{3}\left|\mathrm{u}_{x}\right|^{2}\right) \mathrm{u}_{y}
$$

Where, $\mathrm{u}_{x}$ and $\mathrm{u}_{y}$ denote the envelopes of the optical pulses along the two orthogonal polarization axes of the fiber. $\mathrm{t}$ and $\mathrm{z}$ represent the time and the propagation distance, respectively. $\beta=\frac{\pi \Delta n}{\lambda}$ and $\delta=\frac{\beta \lambda}{2 \pi c}$ are the wavenumber difference and inverse group velocity difference between the two modes, respectively. $\Delta n$ is the difference of refractive indices for the two orthogonally polarized states, $\lambda$ is the central wavelength for mode-locked operation, and c is the speed of light in vacuum. $\gamma$ is the cubic refractive nonlinearity of the fiber. $\Omega_{g}$ is the bandwidth of the laser gain; $g$ is the saturable gain of the fiber and is zero for undoped SMF. For the EDF, the saturation gain can be expressed as $g=g_{0} \exp \left(\frac{-E_{p}}{E_{s}}\right)$, where $g_{0}$, Ep, and Es are the small-signal gain coefficient related to the doping concentration, the pulse energy, and the gain saturation energy that relies on pump power, respectively.

The pulse energy $E_{p}$ is given by:

$$
E_{p}=\int_{-T_{R} / 2}^{T_{R} / 2}\left(\left|\mathrm{u}_{x}\right|^{2}+\left|\mathrm{u}_{y}\right|^{2}\right) d t
$$

Where, $T_{R}$ is the cavity round trip time. To be more precise about the high pulse energy evolution, we consider the parameter optimization problem for the full cavity model. Since we are looking for the parameters that generate the maximum pulse energy, the objective is to construct minimization of perturbation and losses. The total cavity energy, which is given by:

$$
E_{c}=\int_{-\infty}^{\infty} u^{2} d t
$$

In order to implement the high energy mode-locking pulsation, we were required to carefully adjust 
the full cavity along with optimizing of polarization. Therefore, in order to adjust the cavity condition with low loss SA, we added additional fiber iteratively to adjust the dispersion and nonlinear parameter of the cavity. Because of low net cavity loss, high intracavity power confinement is highly anticipated that enhances the nonlinearity of the cavity. At this point, by keeping accounted the power budget, we optimized the cavity by adjusting the dispersion value with extra span of SMF at an optimized state of polarization.

A graphical representation of laser cavity securing high intracavity power is presented in the figure. A combination of low-loss Gf coated 3D IFM SA device with the gain medium (EDFA) that helps to confine high intracavity power; the SA of low insertion loss forms ultrashort and intense pulse, while the EDFA overlaps the feedback modes with gain thereby maximizes the gain efficiency. This mechanism eventually contributes to the extraction of high-energy pulses as well as for ultrashort pulses with high peak power.

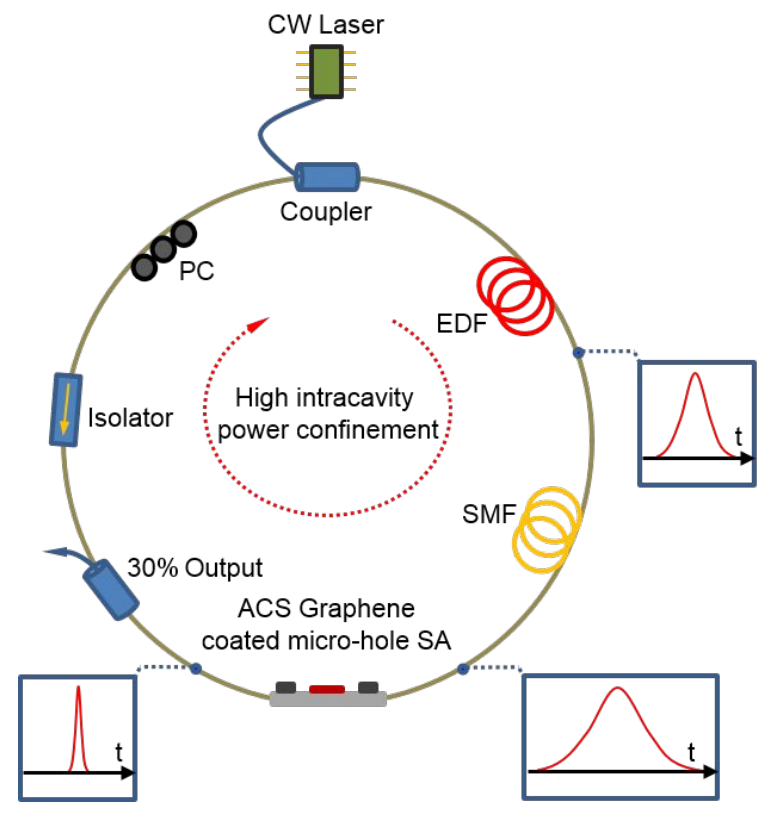

Figure S21: Graphical representation of laser cavity securing high intracavity power. 


\section{Reference}

1. Joubert, J.; Salameh, A.; Krakoviack, V.; Delbecq, F.; Sautet, P.; Copéret, C.; Basset, J. M. Heterolytic Splitting of $\mathrm{H}_{2}$ and $\mathrm{CH}_{4}$ on $\gamma$-Alumina as a Structural Probe for Defect Sites. J. Phys. Chem. B 2006, 110, 23944-23950.

2. Digne, M.; Sautet, P.; Raybaud, P.; Euzen, P.; Toulhoat, H. Use of DFT to Achieve a Rational Understanding of Acid-Basic Properties of $\gamma$-Alumina Surfaces. J. Catal. 2004, 226, 54-68.

3. Lee, M.; Park, K.; Park, J.; Choi, D. K.; Song, Y. W. Oxygen-Dependent Synthesis of Graphene on $\gamma$-Alumina Catalyst. Adv. Mater. Interfaces 2017, 4, 1700603.

4. Robinson, V. N.; Robins, J. L. Nucleation Kinetics of Gold Deposited onto Uhv Cleaved Surfaces of $\mathrm{NaCl}$ and $\mathrm{KBr}$. Thin Solid Films 1974, 20, 155-175.

5. Karger, J.; Ruthven, D. M. Diffusion in Nanoporous Materials: Fundamental Principles, Insights and Challenges. New J. Chem. 2016, 40, 4027-4048.

6. Seitaridou, E.; Inamdar, M. M.; Phillips, R.; Ghosh, K.; Dill, K. Measuring Flux Distributions for Diffusion in the Small-Numbers Limit. J. Phys. Chem. B 2007, 111, 2288-2292.

7. Berry, R. W.; Hall, P. M.; Harris, M. T. Thin Film Technology. Van Nostrand: Princeton, NJ, USA, 1968. 
8. Mu, H. R.; Wang, Z. T.; Yuan, J.; Xiao, S.; Chen, C. Y.; Chen, Y.; Chen, Y.; Song, J. C.; Wang, Y. S.; Xue, Y. Z.; Zhang, H.; Bao, Q. Graphene-Bi $\mathrm{Te}_{3}$ Heterostructure as Saturable Absorber for Short Pulse Generation. ACS Photonics 2015, 2, 832-841.

9. Mu, H. R.; Tuo, M. F.; Xu, C.; Bao, X. Z.; Xiao, S.; Sun, T.; Li, L.; Zhao, L. M.; Li, S. J.; Ren, W. C.; Bao, Q. Graphene and $\mathrm{Mo}_{2} \mathrm{C}$ Vertical Heterostructure for Femtosecond Mode-Locked Lasers [Invited]. Opt. Mater. Express 2019, 9, 3268-3276.

10. Bao, Q. L.; Zhang, H.; Ni, Z. H.; Wang, Y.; Polavarapu, L.; Shen, Z. X.; Xu, Q. H.; Tang, D. Y.; Loh, K. P. Monolayer Graphene as a Saturable Absorber in a Mode-Locked Laser. Nano Res. 2011, 4, 297-307.

11. Zhang, H.; Bao, Q. L.; Tang, D. Y.; Zhao, L. M.; Loh, K. Large Energy Soliton ErbiumDoped Fiber Laser with a Graphene-Polymer Composite Mode Locker. Appl. Phys. Lett. 2009, 95, 141103.

12. Bao, Q. L.; Zhang, H.; Wang, Y.; Ni, Z. H.; Yan, Y. L.; Shen, Z. X.; Loh, K. P.; Tang, D. Y. Atomic-Layer Graphene as a Saturable Absorber for Ultrafast Pulsed Lasers. $A d v$. Funct. Mater. 2009, 19, 3077-3083.

13. Liu, S. X.; Li, Z. J.; Ge, Y. Q.; Wang, H. D.; Yue, R.; Jiang, X. T.; Li, J. Q.; Wen, Q.; Zhang, H. Graphene/Phosphorene Nano-Heterojunction: Facile Synthesis, Nonlinear Optics, and Ultrafast Photonics Applications with Enhanced Performance. Photonics Res 2017, 5, 662-668.

14. Zhao, J. Q.; Wang, Y. G.; Ruan, S. C.; Yan, P. G.; Zhang, H.; Tsang, Y. H.; Yang, J. H.; Huang, G. X. Three Operation Regimes with an L-Band Ultrafast Fiber Laser Passively 
Mode-Locked by Graphene Oxide Saturable Absorber. J. Opt. Soc. Am. B 2014, 31, 716722.

15. Zheng, G. P.; Chen, Y.; Huang, H. H.; Zhao, C. J.; Lu, S. B.; Chen, S. Q.; Zhang, H.;

Wen, S. C. Improved Transfer Quality of CVD-Grown Graphene by Ultrasonic Processing of Target Substrates: Applications for Ultra-Fast Laser Photonics. ACS Appl. Mater. Inter. 2013, 5, 10288-10293.

16. Feng, Q.; Chen, Y.; Zhao, C. J.; Li, Y.; Wen, J. G.; Zhang, H. Experimental Study on the Multisoliton Pattern Formation in an Erbium-Doped Fiber Laser Passively Mode-Locked by Graphene Saturable Absorber. Opt. Eng. 2013, 52, 044201.

17. Sun, Z. P.; Popa, D.; Hasan, T.; Torrisi, F.; Wang, F. Q.; Kelleher, E. J. R.; Travers, J. C.; Nicolosi, V.; Ferrari, A. C. A Stable, Wideband Tunable, Near Transform-Limited, Graphene-Mode-Locked, Ultrafast Laser. Nano Res. 2010, 3, 653-660.

18. Popa, D.; Sun, Z.; Torrisi, F.; Hasan, T.; Wang, F.; Ferrari, A. C. Sub 200 fs Pulse Generation from a Graphene Mode-Locked Fiber Laser. Appl. Phys. Lett. 2010, 97, 203106.

19. Zhang, M.; Kelleher, E. J. R.; Torrisi, F.; Sun, Z.; Hasan, T.; Popa, D.; Wang, F.; Ferrari, A. C.; Popov, S. V.; Taylor, J. R. Tm-Doped Fiber Laser Mode-Locked by GraphenePolymer Composite. Opt. Express 2012, 20, 25077-25084.

20. Li, L. F.; Zheng, X. L.; Chen, X. M.; Qi, M.; Ren, Z. Y.; Bai, J. T.; Sun, Z. P. HighPower Diode-Side-Pumped Nd:YAG Solid Laser Mode-Locked by CVD Graphene. Opt. Commun. 2014, 315, 204-207. 
21. Martinez, A.; Fuse, K.; Xu, B.; Yamashita, S. Optical Deposition of Graphene and Carbon Nanotubes in a Fiber Ferrule for Passive Mode-Locked Lasing. Opt. Express 2010, 18, 23054-23061.

22. Sobon, G.; Sotor, J.; Abramski, K. M. Passive Harmonic Mode-Locking in Er-Doped Fiber Laser Based on Graphene Saturable Absorber with Repetition Rates Scalable to 2.22 GHz. Appl. Phys. Lett. 2012, 100, 161109.

23. Sotor, J.; Sobon, G.; Abramski, K. M. Scalar Soliton Generation in All-PolarizationMaintaining, Graphene Mode-Locked Fiber Laser. Opt. Lett. 2012, 37, 2166-2168.

24. Sotor, J.; Sobon, G.; Krzempek, K.; Abramski, K. M. Fundamental and Harmonic ModeLocking in Erbium-Doped Fiber Laser Based on Graphene Saturable Absorber. Opt. Commun. 2012, 285, 3174-3178.

25. Sotor, J.; Sobon, G.; Abramski, K. M. Er-Doped Fibre Laser Mode-Locked by Mechanically Exfoliated Graphene Saturable Absorber. Opto-Electron Rev. 2012, 20, $362-366$.

26. Sobon, G.; Sotor, J.; Pasternak, I.; Strupinski, W.; Krzempek, K.; Kaczmarek, P.; Abramski, K. M. Chirped Pulse Amplification of a Femtosecond Er-Doped Fiber Laser Mode-Locked by a Graphene Saturable Absorber. Laser Phys. Lett. 2013, 10, 035104

27. Sobon, G.; Sotor, J.; Pasternak, I.; Krzempek, K.; Strupinski, W.; Abramski, K. M. A Tunable, Linearly Polarized Er-Fiber Laser Mode-Locked by Graphene/PMMA Composite. Laser Phys. 2013, 23, 125101. 
28. Tarka, J.; Sobon, G.; Boguslawski, J.; Sotor, J.; Jagiello, J.; Aksienionek, M.; Lipinska, L.; Zdrojek, M.; Judek, J.; Abramski, K. M. 168 fs Pulse Generation from GrapheneChitosan Mode-Locked Fiber Laser. Opt. Mater. Express 2014, 4, 1981-1986.

29. Sotor, J.; Pasternak, I.; Krajewska, A.; Strupinski, W.; Sobon, G. Sub-90 fs a StretchedPulse Mode-Locked Fiber Laser Based on a Graphene Saturable Absorber. Opt. Express 2015, 23, 27503-27508.

30. Boguslawski, J.; Sobon, G.; Pasternak, I.; Krajewska, A.; Struphiski, W.; Abramski, K. M.; Sotor, J. Bound Soliton State in All-Polarization Maintaining Fiber Laser ModeLocked by Graphene. XIth Symposium on Laser Technology, Laser Technology 2016: Progress and Applications of Lasers, Jastarnia, Poland, 26-30 September 2016; SPIE 2016, 10159, 1015907.

31. Sotor, J.; Sobon, G. 24 fs and 3 nJ Pulse Generation from a Simple, All Polarization Maintaining Er-Doped Fiber Laser. Laser Phys. Lett. 2016, 13, 125102.

32. Tamura, K.; Ippen, E. P.; Haus, H. A.; Nelson, L. E., 77-fs Pulse Generation from a Stretched-Pulse Mode-Locked All-Fiber Ring Laser. Opt. Lett. 1993, 18, 1080-1082.

33. Chong, A.; Buckley, J.; Renninger, W.; Wise, F. All-Normal-Dispersion Femtosecond Fiber Laser. Opt. Exp. 2006, 14, 10095-10100.

34. Lim, H.; Ilday, F. Ö.; Wise, F. W. Generation of 2-nJ Pulses from a Femtosecond Ytterbium Fiber Laser. Opt. Lett. 2003, 28, 660-662.

35. Lecourt, J.-B.; Duterte, C.; Narbonneau, F.; Kinet, D.; Hernandez, Y.; Giannone, D. AllNormal Dispersion, All-Fibered PM Laser Mode-Locked by SESAM. Opt. Express 2012, 20, 11918-11923. 
36. Kieu, K.; Wise, F. W. All-Fiber Normal-Dispersion Femtosecond Laser. Opt. Express 2008, $16,11453-11458$.

37. Du, J.; Zhang, S. M.; Li, H. F.; Meng, Y. C.; Li, X. L.; Hao, Y. P. L-Band Passively Harmonic Mode-Locked Fiber Laser Based on a Graphene Saturable Absorber. Laser Phys. Lett. 2012, 9, 896-900.

38. Chong, A.; Renninger, W. H.; Wise, F. W. Properties of Normal-Dispersion Femtosecond Fiber Lasers. J. Opt. Soc. Am. B 2008, 25, 140-148.

39. Mortag, D.; Wandt, D.; Morgner, U.; Kracht, D.; Neumann, J. Sub-80-fs Pulses from an All-Fiber-Integrated Dissipative-Soliton Laser at $1 \mu \mathrm{m}$. Opt. Exp. 2011, 19, 546-551.

40. Kharenko, D. S.; Podivilov, E. V.; Apolonski, A. A.; Babin, S. A. 20 nJ 200 fs All-Fiber Highly Chirped Dissipative Soliton Oscillator. Opt. Lett. 2012, 37, 4104-4106.

41. Kharenko, D. S.; Gonta, V. A.; Babin, S. A. 50 nJ 250 fs All-Fibre Raman-Free Dissipative Soliton Oscillator. Laser Phys. Lett. 2016, 13, 025107.

42. Zhao, N.; Liu, M.; Liu, H.; Zheng, X.-W.; Ning, Q.-Y.; Luo, A.-P.; Luo, Z.-C.; Xu, W.C. Dual-Wavelength Rectangular Pulse Yb-Doped Fiber Laser Using a Microfiber-Based Graphene Saturable Absorber. Opt. Express 2014, 22, 10906-10913.

43. Fu, B.; Hua, Y.; Xiao, X.; Zhu, H.; Sun, Z.; Yang, C. Broadband Graphene Saturable Absorber for Pulsed Fiber Lasers at 1, 1.5, and $2 \mu \mathrm{m}$. IEEE J. Sel. Top. Quantum Electron. 2014, 20, 411-415.

44. Cheng, Z.; Wu, S.; Yang, Q.-H.; Wang, P. Square Pulse Generation from All-NormalDispersion Graphene Oxide Mode-Locked Yb-Doped Fiber Laser. CJ Poster Session (CJ_P), 2013 Conference on Lasers and Electro-Optics - International Quantum 
Electronics Conference, Munich, Germany, 12-16 May 2013; Optical Society of America: USA, 2013; paper CJ_P_24.

45. Huang, S.; Wang, Y.; Yan, P.; Zhao, J.; Li, H.; Lin, R. Tunable and Switchable MultiWavelength Dissipative Soliton Generation in a Graphene Oxide Mode-Locked YbDoped Fiber Laser. Opt. Exp. 2014, 22, 11417-11426.

46. Zhao, N.; Luo, Z. C.; Liu, H.; Liu, M.; Zheng, X. W.; Liu, L.; Liao, J. H.; Wang, X. D.; Luo, A. P.; Xu, W. C. Trapping of Soliton Molecule in a Graphene-Based Mode-Locked Ytterbium-Doped Fiber Laser. IEEE Photon. Technol. Lett. 2014, 26, 2450-2453.

47. Luo, Z.; Huang, Y.; Wang, J.; Cheng, H.; Cai, Z.; Ye, C. Multiwavelength DissipativeSoliton Generation in Yb-Fiber Laser Using Graphene-Deposited Fiber-Taper. IEEE Photon. Technol. Lett. 2012, 24, 1539-1542.

48. Huang, S.; Wang, Y.; Peiguang, Y.; Zhang, G.; Zhao, J.; Li, H.; Lin, R.; Cao, G.; Duan, J. Observation of Multipulse Bunches in a Graphene Oxide Passively Mode-Locked Ytterbium-Doped Fiber Laser with All-Normal Dispersion. Appl. Phys. B 2014, 116, 939946.

49. Li, X. H.; Wang, Y. G.; Wang, Y. S.; Zhang, Y. Z.; Wu, K.; Shum, P. P.; Yu, X.; Zhang, Y.; Wang, Q. J. All-Normal-Dispersion Passively Mode-Locked Yb-Doped Fiber Ring Laser Based on a Graphene Oxide Saturable Absorber. Laser Phys. Lett. 2013, 10, 075108.

50. Huang, S. S.; Wang, Y. G.; Yan, P. G.; Zhang, G. L.; Zhao, J. Q.; Li, H. Q.; Lin, R. Y. Soliton Rains in a Graphene-Oxide Passively Mode-Locked Ytterbium-Doped Fiber Laser with All-Normal Dispersion. Laser Phys. Lett. 2013, 11, 025102. 
51. Hong, S.; Lédée, F.; Park, J.; Song, S.; Lee, H.; Lee, Y. S.; Kim, B.; Yeom, D.-I.;

Deleporte, E.; Oh, K. Mode-Locking of All-Fiber Lasers Operating at Both Anomalous and Normal Dispersion Regimes in the C- and L-Bands Using Thin Film of 2D Perovskite Crystallites. Laser \& Photon. Rev. 2018, 12, 1800118.

52. Khazaeinezhad, R.; Kassani, S. H.; Jeong, H.; Nazari, T.; Yeom, D.; Oh, K. ModeLocked All-Fiber Lasers at Both Anomalous and Normal Dispersion Regimes Based on Spin-Coated $\mathrm{MoS}_{2}$ Nano-Sheets on a Side-Polished Fiber. IEEE Photon. J. 2015, 7, 1-9. 